\title{
Fibroblast Growth Factor Signaling Is Required for the Generation of Oligodendrocyte Progenitors from the Embryonic Forebrain
}

\author{
Miki Furusho, ${ }^{1}$ Yoshimi Kaga, ${ }^{1}$ Akihiro Ishii, ${ }^{1}$ Jean M. Hébert, ${ }^{2}$ and Rashmi Bansal ${ }^{1}$ \\ ${ }^{1}$ Department of Neuroscience, University of Connecticut Medical School, Farmington, Connecticut 06030, and ${ }^{2}$ Department of Neuroscience and Molecular \\ Genetics, Albert Einstein College of Medicine, Bronx, New York 10461
}

Fibroblast growth factors (FGFs) comprise a family of developmental regulators implicated in a wide variety of neurological functions. FGF receptors 1, 2, and 3 (Fgfrs) are expressed in the embryonic forebrain, including regions overlapping with ventral sites of oligodendrocyte progenitor (OLP) generation. Although FGF signaling is known to influence the proliferation of OLPs in vitro, functions of different Fgfrs in vivo are lacking. Here, we examined single and double mutants with conditional disruption of Fgfrs, specifically in the embryonic forebrain, to investigate the effect of FGFs on the generation and proliferation of OLPs in vivo. FGF signaling, through cooperation between Fgfr1 and Fgfr2 but not $F g f r 3$, is required for the initial generation of OLPs in the mouse ventral forebrain, with Fgfr 1 being a stronger inducer than Fgfr2. In cultures derived from embryonic mutant forebrains or from normal forebrains grown in the presence of Fgfr inhibitor, a strong attenuation of OLP generation was observed, supporting the role of FGF signaling in vivo. Contrary to in vitro findings, Fgfr1 and Fgfr2 signaling is not required for the proliferation of OLPs in vivo. Finally, failure of OLP generation in the Fgfr mutants occurred without loss of sonic hedgehog (Shh) signaling; and pharmacological inhibition of either Fgfr or hedgehog signaling in parallel cultures strongly inhibited OLP generation, suggesting that Fgfrs cooperate with Shh to generate OLPs. Overall, our results reveal for the first time an essential role of FGF signaling in vivo, where the three Fgfrs differentially control the normal generation of OLPs from the embryonic ventral forebrain.

\section{Introduction}

Oligodendrocyte progenitor populations that are embryonically generated originate in the ventral forebrain and then migrate dorsally to their final destinations in the cerebral cortex (TekkiKessaris et al., 2001; Miller, 2002; Rowitch, 2004; Kessaris et al., 2008), sequentially maturing through a series of stages (Pfeiffer et al., 1993; Espinosa-Jeffrey et al., 2009). It is generally believed that these cells, expressing the transcription factor Olig2 and plateletderived growth factor receptor- $\alpha$ (Pdgfra), are generated under the regulation of sonic hedgehog (Shh) (Alberta et al., 2001; Nery et al., 2001; Spassky et al., 2001; Tekki-Kessaris et al., 2001; Fuccillo et al., 2004; Rowitch, 2004). However, evidence has emerged that oligodendrocyte progenitor (OLP) generation may depend on signals in addition to Shh (Nery et al., 2001; Chandran et al., 2003; Gabay et al., 2003; Kessaris et al., 2004; Cai et al., 2005; Abematsu et al., 2006).

Fibroblast growth factors (FGFs) are a family of signaling molecules that play diverse roles in regulating the development of the nervous system, often in intimate association with other de-

Received Sept. 13, 2010; revised Jan. 4, 2011; accepted Feb. 7, 2011.

This work was supported by National Institutes of Health (NIH) Grant NS38878 and in part by National Multiple Sclerosis Society Grant RG 4087-A-3 and NIH Grant NS41078 (R.B.) and NIH Grant MH070596 (J.M.H.). We thank Dr. D. Ornitz for providing the Fgfr3-null mice; Drs. D. Rowitch, W. D. Richardson, and K. Ikenaka for riboprobes; and Dr. W. B. Stallcup for the PDGFRa antibody.

Correspondence should be addressed to Dr. Rashmi Bansal, Department of Neuroscience, University of Connecticut Medical School, 263 Farmington Avenue, Farmington, CT 06030-3401. E-mail: bansal@neuron.uchc.edu.

DOI:10.1523/JNEUROSCI.4800-10.2011

Copyright $\odot 2011$ the authors $\quad 0270-6474 / 11 / 315055-12 \$ 15.00 / 0$ velopmental regulators (Ford-Perriss et al., 2001; Hébert, 2005; Aboitiz and Montiel, 2007; Mason, 2007). FGF receptors 1-3 (Fgfrs 1-3) are expressed in the forebrain at embryonic day 12.5 (E12.5) in regions that give rise to OLPs, overlapping with Olig2 in the ventral ventricular zone (VZ) (Bansal et al., 2003a). Previous in vitro studies suggest that FGF-2 treatment can induce ventricular cells in culture to acquire an oligodendrocyte (OL) fate (Qian et al., 1997), including dorsally derived neural precursors from the embryonic cerebral cortex (Kessaris et al., 2004; Abematsu et al., 2006) and spinal cord in both a Shh-dependent (Gabay et al., 2003) and -independent (Chandran et al., 2003) manner. We showed that microinjection of FGF-2 into the ventricles of the mouse brain resulted in ectopic induction of OLPs in the embryonic cerebral cortex in a Shh-independent manner (Naruse et al., 2006). In the Fgfr1;Fgfr2 double mutants, ventral forebrain precursors were completely absent (Gutin et al., 2006), mimicking the phenotype of mice lacking Shh signaling (Ericson et al., 1995; Fuccillo et al., 2004). In Fgfr1 or Fgfr2 single mutants, ventral precursors were not lost, and although interneurons were induced normally in Fgfr2 mutants they failed to develop in Fgfr1 mutants (Gutin et al., 2006). Together, these studies suggest that FGFs are likely candidates to regulate OLP generation, through one or more of the three Fgfrs. However, direct genetic evidence for a role of Fgfr signaling in generating the earliest OLP population from its normal origin in the embryonic ventral forebrain is absent.

Using a combination of loss-of-function approaches to genetically and pharmacologically inactivate Fgfr signaling, specifically in the embryonic forebrain, we investigated the role of FGF and 
its relationship to Shh in OLP generation. We provide evidence that, unlike interneurons, FGF signaling through Fgfr 1 as well as Fgfr2 (but not Fgfr3) is required for the generation of OLPs from the ventral forebrain. FGF signaling is not essential for the proliferation or survival of OLPs. Shh signaling remains unaffected in Fgfr-deficient forebrains and cooperates with Fgfr signaling to induce the vast majority of the ventrally derived OLPs in vitro. Thus, the interplay between Fgfr and Shh signaling pathways provides an important mechanism of regulating OLP generation from the embryonic mouse forebrain.

\section{Materials and Methods}

Generation of mutant mice. Conditional single and double knock-out mice in different combinations, with disrupted FGF receptor signaling were previously generated (Gutin et al., 2006). Briefly, floxed alleles of Fgfrl and Fgfr2 genes were used to generate telencephalic specific knockouts when crossed to Foxg1-cre mice, as described previously (Hébert et al., 2003; Yu et al., 2003). The Fgfr3 allele used is a null allele (Deng et al., 1996). Mutant embryos were obtained at the ages indicated in the expected ratios without any signs of necrosis. The transcription factor Foxg1 is expressed from around E8-E9.5 in all cells of the telencephalon, including uncommitted ventral neuroepithelial cells that eventually specify various lineages including the OL lineage (Hébert and McConnell, 2000). Mutant and control embryos were analyzed from the same litters, facilitating comparisons among the genotypes. Since the majority of $F g f r 1$ and $F g f r 2$ mutants rarely survived beyond E17.5, and Fgfr1/Fgfr2 double mutants beyond E14.5, they could not be used to study postnatal OL development.

Tissue preparation. Dams were deeply anesthetized with halothane and pups removed from the uterus. Brains were fixed by immersion in $4 \%$ paraformaldehyde (PFA) in PBS and cryoprotected sequentially in $10 \%$ sucrose followed by $30 \%$ sucrose, each performed overnight at $4{ }^{\circ} \mathrm{C}$ and embedded in OCT compound (Tissue-Tek). Coronal cryostat sections of brains (30 $\mu \mathrm{m}$ thick for E12.5 and $15 \mu \mathrm{m}$ for other ages) were used for in situ hybridization and immunohistochemistry.

In situ hybridization. In situ hybridization was performed with slight modifications of the procedure previously described (Kaga et al., 2006). Riboprobes specific for Olig2, Pdgfra, Sox10, Shh, Patched1, and Foxg1 mRNA were used [gifts from D. Rowitch (University of California, San Franciso, CA), W. Richardson (University College London, London, UK), M. Qui (University of Louisville, Louisville, KY), K. Ikenaka (National Institute for Physiological Sciences, Aichi, Japan), and J. M. Hébert (Albert Einstein College of Medicine, Bronx, NY), respectively]. Briefly, sections were postfixed with 4\% PFA for $15 \mathrm{~min}$, washed in PBS, and incubated in $1 \mu \mathrm{g} / \mathrm{ml}$ proteinase $\mathrm{K}$ at $37^{\circ} \mathrm{C}$ for $30 \mathrm{~min}$. Sections were fixed with $4 \%$ PFA and washed with PBS again. Hybridization for each mRNAs was performed overnight at $65^{\circ} \mathrm{C}(P d g f r a)$ or $70^{\circ} \mathrm{C}(\mathrm{Shh}$, Patched1, Olig2, Foxg1, and Sox10) by using digoxigenin-labeled antisense riboprobes in a solution containing $50 \%$ formamide, $5 \times$ SSC $(750 \mathrm{~mm} \mathrm{NaCl}, 75 \mathrm{~mm}$ trisodium citrate), and $1 \%$ SDS. After hybridization, the sections were washed in $50 \%$ formamide, $2 \times \mathrm{SSC}$, and $1 \%$ SDS at 65 or $70^{\circ} \mathrm{C}$, followed by rinses in $2 \times$ SSC, $0.2 \times$ SSC at room temperature, and $0.1 \times$ SSC at $60^{\circ} \mathrm{C}$. After blocking for nonspecific binding in blocking buffer [Trisbuffered saline, $\mathrm{pH} 7.4$, with $1 \%$ Tween 20 and $1 \%$ normal goat serum (NGS)] for $1 \mathrm{~h}$, sections were incubated for $2 \mathrm{~h}$ in alkaline phosphataseconjugated antidigoxigenin antibody (1:5000; Roche Diagnostics). Color development in the presence of 4-nitroblue tetrazolium chloride, 5-bromo-4-chloro-3-indolylphosphate was performed in the dark at room temperature. The sections were washed in $10 \mathrm{~mm}$ Tris and $10 \mathrm{~mm}$ EDTA, pH 8, incubated in Hoechst blue dye $33342(1 \mathrm{mg} / \mathrm{ml}$; SigmaAldrich) to counterstain the nuclei, fixed in $3.7 \%$ formaldehyde, and mounted with $90 \%$ glycerol.

Comparisons between mutants and controls were made within the same litters. Multiple coronal sections were cut from the rostral to caudal regions of the forebrains. Sections from three separate planes from control and mutant mice were matched using anatomical landmarks. All the "scattered" Olig2 + or Pdgfra + cells in the section were counted from each of the three sections and averaged. Note that Olig2 stains the sections in two distinct patterns: (1) the ventricular zone is stained totally in "solid purple" pattern with no clear cellular distinction, whereas (2) the subventricular region is stained in a "punctate" fashion, which can be clearly distinguished from the solid ventricular zone staining and is defined as scattered cells. Similar staining procedure has been used by other laboratories in previous studies, to reliably quantify these scattered cells as OLPs. The comparison of cell numbers between three and six control and mutant mice was determined by an unpaired Student $t$ test.

Cell culture. Dissociated cultures of whole or ventral portions of forebrains were prepared from E10.5, E11.5, or E12.5 mouse embryos. Briefly, tissue was carefully dissected out from the whole brain and cells were dissociated by trypsinization $\left(0.025 \%\right.$ at $37^{\circ} \mathrm{C}$ for $\left.7 \mathrm{~min}\right)$ and mechanical dissociation. The dissociated cells were plated in $4 \%$ fetal calf serum in DMEM (FCS/DMEM) at a density of $3 \times 10^{5} \mathrm{cells} / \mathrm{cm}^{2}(\mathrm{E} 12.5)$ or $1.5 \times 10^{5}$ cells $/ \mathrm{cm}^{2}(\mathrm{E} 10.5$, E11.5) into polylysine-D-coated $(50 \mathrm{mg} /$ $\mathrm{ml}$; Sigma-Aldrich) four-well culture plates (Nalge Nunc International). Seven hours after plating, the cultures were changed to Bottenstein and Sato defined medium [DMEM with $100 \mu \mathrm{g} / \mathrm{ml}$ transferrin, $5.2 \mathrm{ng} / \mathrm{ml}$ sodium selenium, $5 \mu \mathrm{g} / \mathrm{ml}$ insulin, $8.8 \mu \mathrm{g} / \mathrm{ml}$ putrescine, $6 \mathrm{ng} / \mathrm{ml}$ progesterone, $10,000 \mathrm{U} / \mathrm{ml}$ penicillin, and 10,000 $\mu \mathrm{g} / \mathrm{ml}$ streptomycin (all ingredients from Sigma-Aldrich)] plus $0.5 \%$ FCS. In some experiments as indicated, cells were treated with $N$-[2-[[4-(diethylamino)butyl]amino]-6-(3,5-dimethoxyphenyl) pyrido[2,3- $d$ ] pyrimidin-7-yl]- $N^{\prime}$-(1,1-dimethylethyl)urea (PD173074), a specific inhibitor of Fgfr signaling (Skaper et al., 2000; Bansal et al., 2003b; Kessaris et al., 2004), or cyclopamine, an inhibitor of all hedgehogs including Shh (Enzo Life Science), at the time when cultures were transferred to defined medium. Since dimethylsulfoxide (DMSO) was used to dissolve the inhibitors, it was added to the control cultures. Every $4 \mathrm{~d}$, one-half of the medium was changed with the readdition of inhibitors wherever needed.

Immunofluorescence microscopy. Cells in mixed primary cultures from embryonic forebrains were immunolabeled for successive stage-specific markers of the OL lineage. Pre/early OLPs were identified with Olig2 and PDGFRa antibodies, late OLPs with O4 antibody, and mature OLs with HPC7 antibody (Pfeiffer et al., 1993; Baas and Barnstable, 1998).

Cells in culture were labeled as described previously (Bansal et al., 1996). Briefly, O4 and HPC7 labeling was done on live cells on ice; and PDGFRa and Olig2 staining was performed after fixation of cells with $4 \%$ PFA for $10 \mathrm{~min}$ and permeabilization with $0.1 \%$ Triton X-100 in HEPESbuffered Earl's balanced salt solution for $5 \mathrm{~min}$. Cells were blocked with $3 \%$ NGS in PBS for $1 \mathrm{~h}$ and incubated with primary antibodies [mouse monoclonal IgM O4 antibody, 1:25; mouse monoclonal IgG HPC7 antibody, 1:25 (C. J. Barnstable, Penn State College of Medicine, Hershey, PA); rabbit anti-Olig2, 1:50 (IBL); rabbit anti-PDGFRa, 1:200 (W. B. Stallcup, Burham Institute, La Jolla, CA); rat anti-PDGFRa, 1:100 (BD Biosciences)] for $1 \mathrm{~h}$, washed, and incubated with the appropriate secondary antibodies [ $\mu$-chain-specific goat anti-mouse IgM-fluorescein, 1:50; $\gamma$-chain-specific goat anti-mouse IgG-Cy3, 1:600; donkey anti-rabbit IgG-Cy3, 1:600 (all from Jackson ImmunoResearch) or goat anti-rabbit IgG-Alexa 488, 1:200 (Invitrogen)] for $1 \mathrm{~h}$. Total cells were identified by incubating with the nuclear stain Hoechst Blue 33342 (1:1000), along with secondary antibodies. Cells were washed and mounted in 1,4diazobicyclo-(2,2,2)-octane in glycerol (DABCO). Immunolabeled cells were counted in 75-150 $20 \times$ fields to provide an accurate sampling of the positive cell distribution on the whole plate.

Immunohistochemistry. After antigen retrieval by heat treatment $\left(95^{\circ} \mathrm{C}, 5 \mathrm{~min}\right)$, the E12.5 forebrain sections were incubated in $0.05 \%$ $\mathrm{H}_{2} \mathrm{O}_{2}$ in PBS for 30 min to inactivate endogenous peroxidase. Next, the sections were blocked in $10 \%$ normal goat serum, $0.2 \%$ Triton X-100 for $1 \mathrm{~h}$, and then incubated overnight $\left(4^{\circ} \mathrm{C}\right)$ in rabbit pan-Erk1/2 antibody (1:500; Promega). Sections were then incubated in biotinylated antirabbit IgG (1:200; Vector Laboratories) for $1 \mathrm{~h}$ and in ABC reagents (VECTASTAIN Elite ABC kit: Vector Laboratories) for $40 \mathrm{~min}$ at room temperature before color development with $0.05 \%$ 3-3-diaminobenzidine/0.015\% $\mathrm{H}_{2} \mathrm{O}_{2}$ (DAB) (Research Genetics). Parallel sections processed identically but without the incubation in the primary antibody served as negative controls.

Proliferation assay. To identify OLPs that were in the S-phase of the cell cycle, mice received an intraperitoneal injection of bromodeoxyuridine (BrdU) (100 mg/kg body weight) for incorporation into newly synthesized DNA and killed $1 \mathrm{~h}$ later. Tissue preparation and sectioning were 
performed as described above. After detection of Pdgfra by in situ hybridization, the sections were incubated in preheated citrate buffer $(10 \mathrm{~mm})$, $\mathrm{pH} 6.0$, for $5 \mathrm{~min}$ at $95^{\circ} \mathrm{C}$. After $1 \mathrm{~h}$ of blocking in $10 \% \mathrm{NGS}$ and $0.2 \%$ Triton X-100 in PBS, the sections were incubated overnight with mouse monoclonal anti-BrdU (1:25; BD Biosciences), washed three times, and incubated for $1 \mathrm{~h}$ with a biotinylated goat anti-mouse IgG (1:200; Vector Laboratories). The sections were next incubated with avidin-biotin peroxidase complex (VECTASTAIN Elite ABC kit) for $40 \mathrm{~min}$ at room temperature, and the immune complexes were visualized by treatment with DAB. To identify mitotic cells, the sections were stained with antiphosphohistone ( $\mathrm{pH} 3$ Ser10) antibody (1:200; Millipore). Sections were fixed with 4\% PFA for 10 min, blocked with 1\% NGS in PBS containing $0.1 \%$ Triton X-100 for $1 \mathrm{~h}$, and incubated with the antibody overnight. The sections were then washed and incubated with goat anti-rabbit Alexa 488 (1:200) and Hoechst blue 33342 (1:1000) and washed and mounted in DABCO.

To detect proliferating cells in culture, BrdU was added to the cultures for $3 \mathrm{~h}$ at a final concentration of $50 \mu \mathrm{M}$. After labeling with either rabbit antiOlig2 or rabbit anti-PDGFRa as described above, the cells were fixed with $4 \%$ PFA, washed with PBS, incubated with acid alcohol (95\% ethanol/ $5 \%$ acetic acid) for $2 \mathrm{~min}$ at $-20^{\circ} \mathrm{C}$, washed in PBS, denatured with $2 \mathrm{~N} \mathrm{HCl}(10 \mathrm{~min})$, neutralized with $0.1 \mathrm{M}, \mathrm{pH} 8.5$, sodium borate buffer ( $10 \mathrm{~min}$ ), blocked with $3 \% \mathrm{NGS} / \mathrm{PBS}(1 \mathrm{~h})$, and incubated in mouse monoclonal anti-BrdU antibody for $30 \mathrm{~min}$. Cells were washed in PBS, incubated in goat anti-mouse IgG conjugated to Cy3 (1:600; Jackson ImmunoResearch) and Hoechst Blue 33342 (1:1000), and washed and mounted.

Apoptotic cells assay. Apoptotic cells were detected using terminal deoxynucleotide transferase-mediated dUTP-biotin nick end labeling (TUNEL) assay (ApopTag kit; Invitrogen) according to the manufacturer's protocol. Briefly, brain cryosections were incubated in 4\% PFA for 30 min, treated with $0.3 \% \mathrm{H}_{2} \mathrm{O}_{2}$ to quench endogenous peroxidase, washed in equilibrium buffer, and incubated in reaction buffer containing digoxygenin-dNTP and terminal deoxynucleotidyl transferase (30 min, $37^{\circ} \mathrm{C}$ ). The sections were washed and incubated for $30 \mathrm{~min}$ with peroxidase conjugate anti-digoxygenin. The TUNEL + cells were identified by reaction with $\mathrm{DAB}$ and analyzed by epifluorescence microscopy.

Immunoblotting. Dorsal and ventral forebrain tissue from E12.5 normal mice were separated and mechanically dissociated in N2 medium (Fortin et al., 2005). After $30 \mathrm{~min}$ of recovery at $37^{\circ} \mathrm{C}, 0.2 \mu \mathrm{g} / \mathrm{ml}$ heparin was added to both cell suspensions and each divided equally into six samples for different treatments as indicated. Cells were incubated in FGF-2 (50 ng/ml) or FGF-8 $(50 \mathrm{ng} / \mathrm{ml})$ for $15 \mathrm{~min}$ at $37^{\circ} \mathrm{C}$. Incubation with Fgfr inhibitor, PD173074 (100 nM), or DMSO was for $1 \mathrm{~h}$ before FGF-2 addition. Cells were centrifuged and pellets were lysed in RIPA buffer (10 mm Tris-HCl, $150 \mathrm{~mm} \mathrm{NaCl}, 0.1 \%$ SDS, 1\% deoxycholate, and $1 \% \mathrm{NP}-40, \mathrm{pH} 7.4)$ with protease and phosphatase inhibitors $(2 \mathrm{~mm}$ PMSF, $2 \mu \mathrm{g} / \mathrm{ml}$ leupeptin, $2 \mu \mathrm{g} / \mathrm{ml}$ aprotinin, $50 \mathrm{~mm} \mathrm{NaF}, 10 \mathrm{~mm}$ $\mathrm{NaP}_{2} \mathrm{O}_{7}$, and $1 \mathrm{~mm} \mathrm{Na} o$-vanadate) and briefly sonicated and centrifuged. As described previously (Fortin et al., 2005), total protein was assayed in each sample, and equal amounts $(2.5 \mu \mathrm{g})$ were loaded on SDS-PAGE gel, transferred to PVDF (polyvinylidene difluoride) membrane, and immunolabeled with mouse monoclonal anti-phospho-Erk1/2 (1:1000; Sigma-Aldrich) or rabbit pan-Erk1/2 antibody (1:5000; Promega) followed by HRP-conjugated goat anti-mouse or goat anti-rabbit secondary antibody (1:10,000; Santa Cruz Biotechnology), and developed with ECL Plus reagent (GE Healthcare).

\section{Results}

\section{$F g f r 1$ and $F g f r 2$, but not $F g f r 3$ are required for the generation} of OL progenitor from the embryonic mouse forebrain

We asked whether the generation of OL progenitors in vivo from the embryonic ventral forebrain was affected by the absence of Fgfr1, Fgfr2, and/or Fgfr3. We examined controls and single mutants of these receptors at E12.5 by in situ hybridization for the expression of Pdgfra and Olig2 to determine the extent of OLP generation (Fig. $1 A-C$ ). In the normal embryonic forebrains, $P d g f r a$ marks the earlier population of OLPs that appear as an array of scattered cells in the ventral VZ and subventricular zones,
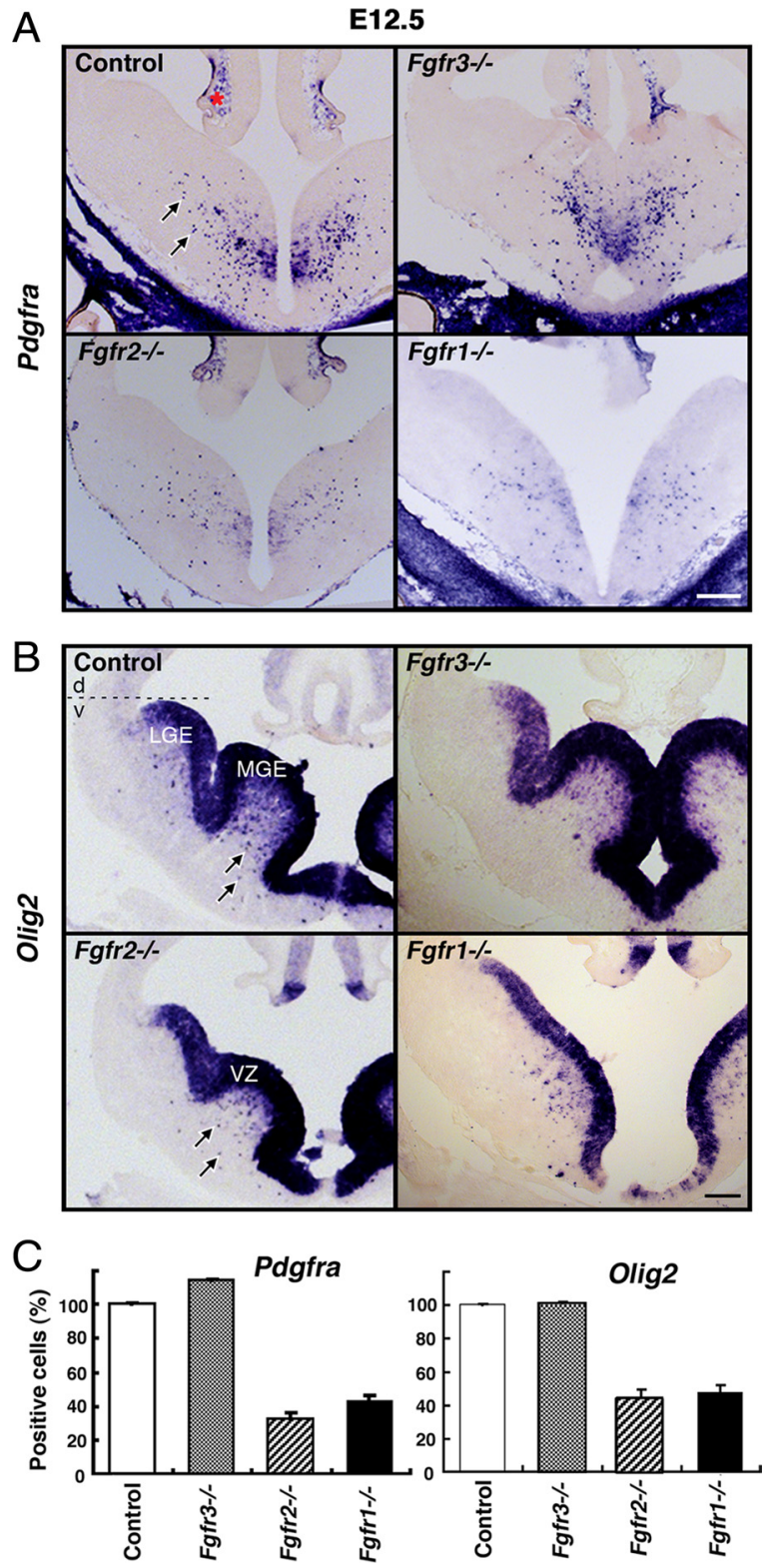

Figure 1. Fgfr1 and Fgfr2, but not Fgfr3, are required for the generation of $0 \mathrm{~L}$ progenitor from the embryonic mouse forebrains. Coronal sections of E12.5 forebrains from control, $\mathrm{Fgfr}^{-1-}$, Fgfr ${ }^{-1-}$, or Fgfr $3^{-1-}$ mutants were analyzed for the expression of OLP markers Pdgfra $(\boldsymbol{A})$ or Olig2 $(\boldsymbol{B})$ mRNA by in situ hybridization. Total numbers of scattered Pdgfra + or Olig2 + cells (arrows) were counted in the whole forebrain sections taken caudally (Pdgfra) or rostrally (0lig2). Three to four matched sections from each littermate control and mutant mice were analyzed. Numbers of animals analyzed were six each of control, $\mathrm{Fgfr}^{-1-}$, or Fgfr2 ${ }^{-1-}$ and two of Fgfr $3^{-1-}$. Data are expressed as percentage of control ( $($ ). Error bars represent SEM. Scale bars, $200 \mu \mathrm{m}$. Pdgfra expression is also visible in the meninges $\left({ }^{*}\right)$. Note that, compared with controls, decreased numbers of OLPs were found in both $\mathrm{Fgfr}^{-1-}$ and $\mathrm{Fgfr} 2^{-1-}$ mutants regardless of abnormal ventral forebrain morphology in the Fgfr ${ }^{-1-}$ mutants. All the mutants maintained the expression of Olig2 in the ventral VZ of the MGE and LGE, suggesting normal dorsoventral patterning. The dotted line defines the boundary between the dorsal neocortical (d) and the ventral forebrain (v) regions.

first localized in the anterior entopeduncular area, later extending into the median and lateral ganglionic eminences (MGE, LGE), and then migrating dorsally to the neocortex (Fig. 1A) (Nery et al., 2001; Tekki-Kessaris et al., 2001). Olig2 is normally expressed strongly in the ventral VZ lining the ventricles terminating sharply at the corticostriatal boundary and in scattered cells outside the VZ, which are presumably OLPs (Fig. $1 B$ ) (Alberta 
et al., 2001; Tekki-Kessaris et al., 2001). Although the VZ expression of Olig2 was unaffected, there was a dramatic decrease in the numbers of scattered Olig2+, Pdgfra+ OLPs that appeared in the ventral forebrain of Foxg $1^{\text {cre/+ }}$;Fgfr $1^{\text {lox/lox }}$ or Foxg $1^{\text {cre/+}}$; Fgfr $2^{\text {lox/lox }}$ mutants (will be referred to as Fgfr $1^{-/-}$or $\mathrm{Fgfr} 2^{-/-}$) compared with littermate controls (Fig. $1 A-C$ ) or heterozygous receptor mutants (data not shown). In contrast, even though Fgfr3 is expressed in the ventral $\mathrm{VZ}$ in a pattern similar to $F g f r 1$ and Fgfr2 (Bansal et al., 2003a), its loss did not have any effect on OLP generation (Fig. $1 A-C)$. Sox10, another marker of OLPs, was also examined showing a reduction of Sox10+ scattered cells in the mutants similar to $P d g f r a$ (data not shown). In agreement with the previous finding (Gutin et al., 2006), the morphology of the ventral forebrain was affected in the $F g f r 1^{-1-}$, but not Fgfr $2^{-l-}$, mutants (Fig. $1 B$ ). Regardless of this structural defect, OLP generation was equally perturbed in both $F g f r 1^{-1-}$ and Fgfr2 ${ }^{-1-}$ mutants, suggesting that it occurred independent of morphological defects. This notion is further supported by our observation (presented later) (see Fig. 3) that OLP production was also deficient in dissociated cell cultures derived from E12.5 Fgfr $1^{-1-}$ forebrains.

To investigate whether the reduction of OLP progenitors in the mutant embryos observed at E12.5 reflected a developmental delay, we examined forebrains of Fgfr $1^{-1-}$ or Fgfr2 ${ }^{-1-}$ mutants at E14.5 and E16.5 for the expression of Pdgfra, Sox10, or Olig2 (Fig. 2). Normally by this time, a significant proportion of OLPs progressively migrate from their ventral sites of origin dorsally to the cortical regions. As expected, the numbers of OLPs at these ages were increased in all the groups relative to $\mathrm{E} 12.5$, but the reduction of OLPs was maintained in $F g f r 1^{-1-}$ or Fgfr $2^{-1-}$ embryos compared with controls both in the cortical regions (Fig. 2) and the ventral regions (data not shown), ruling out any significant developmental delay.

It is important to note that, unlike the double $\mathrm{Fgfrl}^{-1-}$; Fgfr $2^{-1-}$ mutant, in the single Fgfr ${ }^{-1-}$ or Fgfr2 ${ }^{-1-}$ mutants the ventral neuroepithelial precursor cells are not lost but clear differences are observed in how the interneuron (Gutin et al., 2006) or OLPs (present study) are generated from these cells at E12.5. Specifically, (1) in the Fgfr 1 single mutants $100 \%$ of the interneurons failed to develop from the neuroepithelial precursors (Gutin et al., 2006); in contrast, $40 \%$ of OLPs were able to develop in these mutants (present study). (2) In Fgfr2 single mutants, interneuron generation was completely unaffected (Gutin et al., 2006 ); in contrast, OLP generation was significantly inhibited in these mutants (by 60\%) (present study).

We conclude that signaling by both Fgfr1 and Fgfr2, but not Fgfr3, is needed to generate the full numbers of ventrally derived OLPs, since loss of either one attenuated the generation of the

A E14.5

B E16.5
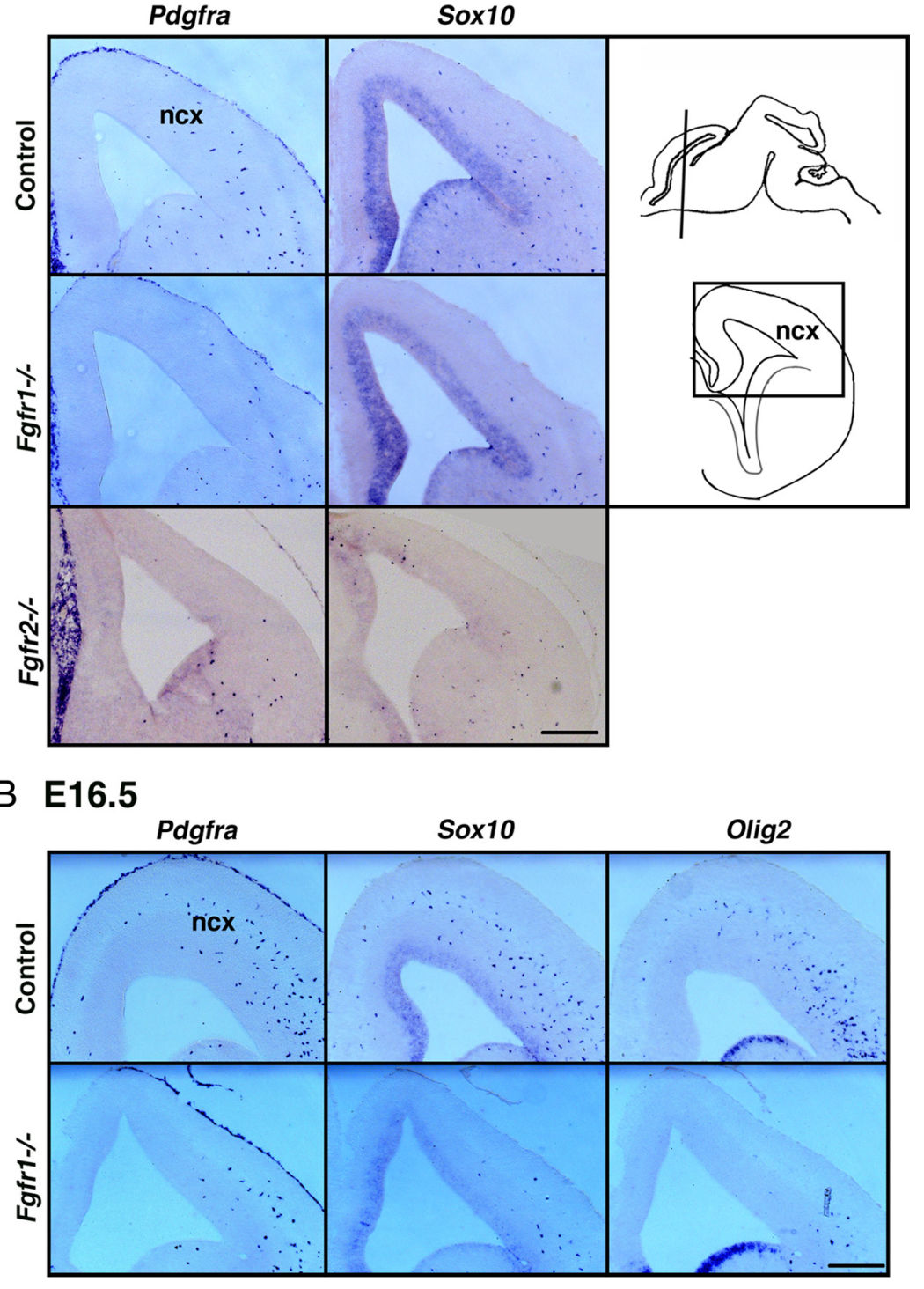

Figure 2. The decrease in $\mathrm{OL}$ progenitors in Fgfr $1^{-1-}$ or Fgfr $2^{-1-}$ mice is maintained even at E14.5 and E16.5. Coronal sections of E14.5 $(\boldsymbol{A})$ or E16.5 (B) forebrains from control, Fgfr ${ }^{-1-}$, or Fgfr ${ }^{-1-}$ mutants were analyzed for the expression of Pdgfra, Sox10, or Olig2 mRNA by in situ hybridization. The diagram shows the plane in which the sections were cut, and the boxed area depicts the neocortical (ncx) region of the forebrain that is shown in the figures. Scale bars, $200 \mu \mathrm{m}$.

majority, but not all of the OLPs. Furthermore, comparison with a previous study (Gutin et al., 2006) demonstrates that there are important differences in the requirements for FGF signaling by ventral neuroepithelial precursors for generating OLPs or interneurons.

Generation of OL progenitors in cultures initiated from E12.5 Fgfr1 $1^{-1-}$ or Fgfr2 ${ }^{-/-}$mutant forebrains is reduced in a manner similar to that in vivo

Lack of Fgfr signaling could potentially disrupt migration of cells out of the germinal zone resulting in reduced numbers of scattered OLPs observed outside the VZ in the Fgfr $1^{-1-}$ and Fgfr2 $2^{-1-}$ mutants (Fig. 1). To test this possibility and to substantiate the in vivo findings, OL progenitor development was analyzed in dissociated cell cultures initiated from E12.5 forebrains of $F g f r 1^{-/-}$or Fgfr2 ${ }^{-1-}$ mutants and their littermate controls (Fig. 3). Cells were examined as a function of time by immunofluorescence microscopic labeling for early OLP markers, Olig2, PDGFRa. As 
A
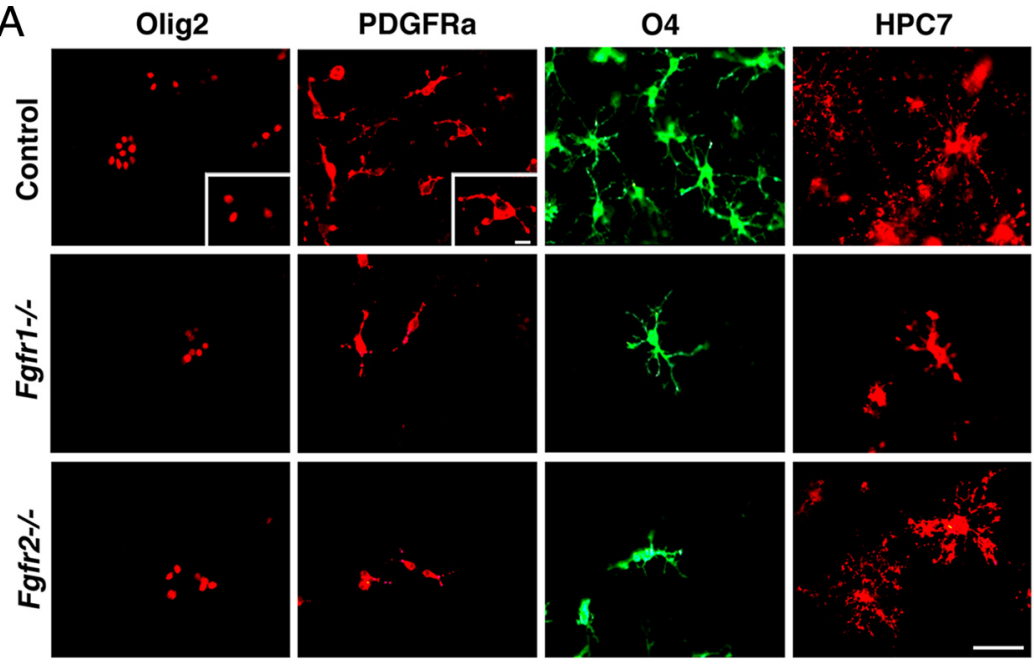

B

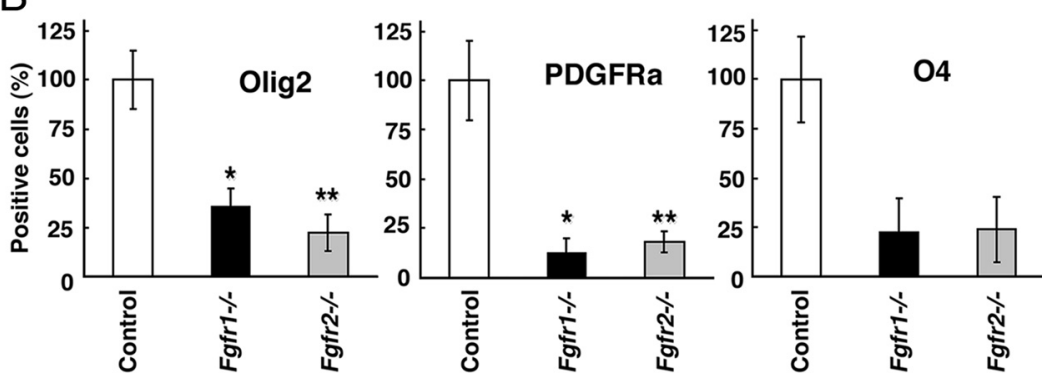

Figure 3. Generation of $\mathrm{OL}$ progenitors in cultures initiated from E12.5 Fgfr $1^{-1-}$ or Fgfr $2^{-1-}$ mutant forebrains is reduced in a manner similar to that in vivo. A, Dissociated cell cultures from E12.5 forebrains of Fgfr ${ }^{-1-}$ or Fgfr2 ${ }^{-1-}$ mutants and littermate controls, were immunolabeled as a function of days in vitro (DIV) for specific markers of pre/early progenitors (0lig2 at 3 DIV and PDGFRa at 6 DIV), late progenitors (04 at 9 DIV), and 0Ls (HPC7 at 12 DIV). $\boldsymbol{B}$, The numbers of 0lig2 +, PDGFRa + , and 04+ cells were counted from each culture and expressed as a percentage of control showing significantly reduced numbers of these cells in both mutants compared with littermate controls. Scale bar, $50 \mu \mathrm{m}$. Error bars represent SEM $\left({ }^{*} p<0.01,{ }^{* *} p<0.02\right)$. Cultures from three to six pups were analyzed for each group.

in vivo, there were reduced numbers of Olig2 + and PDGFRa+ OLP that developed in cultures from each of the two mutant forebrains compared with controls. Since the PDGFRa + OLPs mature into O4+ late OLPs (Pfeiffer et al., 1993), we also examined the expression of the $\mathrm{O} 4$ antigen and found considerably reduced numbers of these cells correlating with the reduced numbers of early OLP marker-expressing cells. Hoechst staining of cell nuclei showed a similar distribution of total cells in cultures of mutant and control forebrains (supplemental Fig. 1, available at www.jneurosci.org as supplemental material). Thus, since reduced numbers of OLPs are also observed in cultures of mutant forebrains, the reduction of OLPs observed in vivo cannot be explained by potential migration defects in the mutants.

Since the mutant mice die before OLPs differentiate into OLs, precluding the in vivo analysis of Fgfr function in the maturation of OLs, we also used these mutant forebrain cultures to analyze OLP terminal differentiation by examining OL marker, HPC7, whose expression overlaps with galactocerebroside, a well recognized marker of OLs (Pfeiffer et al., 1993; Baas and Barnstable, 1998). HPC7 immunolabeling was detected in the cultures of Fgfr $1^{-1-}$ and $F g f r 2^{-1-}$ mutants similar to controls, demonstrating that the small numbers of OLPs that were produced in these mutant cultures were able to differentiate into OLs. However, the proportion of late progenitors that differentiated into OLs was not determined here and is being examined in another study that addresses the role of FGF signaling at later stages of OLP maturation.

\section{Loss of Fgfr1 or Fgfr2 does not affect proliferation or cell death of $\mathrm{OL}$ progenitors}

The reduction in the numbers of OLPs observed in the Fgfr1 $1^{-1-}$ and Fgfr2 ${ }^{-1-}$ mutants could, in principle, be attributable to a decreased efficiency of specification by the neuroepithelial cells toward an OL progenitor fate, reduced proliferation, and/or increased death of specified cells. To explore these possibilities, we examined the proliferation and cell death in the E12.5 forebrains of mutants and their littermate controls. The proliferative capacity of OLPs was studied in vivo by injecting BrdU intraperitoneally into mothers, $1 \mathrm{~h}$ before harvesting brains from the embryos, for the analysis of Olig2 or Pdgfra mRNA-positive cells double labeled with anti-BrdU (Fig. 4A). Proliferation of OLPs was also studied in cultures initiated from E12.5 control and mutant forebrains (Fig. $4 B$ ). No differences were observed in the numbers of OLPs incorporating BrdU in control and $\mathrm{Fgfr} 2^{-1-}$ or Fgfr $1^{-1-}$ mutants either in vivo or in vitro. Similarly, immunolabeling of mutant and control forebrains with anti-phosphohistone 3 ( $\mathrm{pH} 3$ ) (a marker for mitotic cells) also did not show any significant differences in the numbers of $\mathrm{pH} 3+$ cells (Fig. 4C). These data suggest that the proliferation of OLPs is not affected in the forebrains of Fgfr1 ${ }^{-1-}$ and $\mathrm{Fgfr}^{-1-}$ mutants and therefore cannot account for the reduced numbers of OLPs.

The reduced numbers of OLPs observed in the Fgfr $1^{-1-}$ and Fgfr2 ${ }^{-1-}$ mutants can also be attributed to a localized increase in ventral forebrain cell death. It has been previously reported that in the $F g f r 1^{-1-} ; F g f r 2^{-1-}$ double mutants at E10.5, there is increased cell death in the dorsal midline compared with control, and in the Foxg $1^{\text {cre/+ }}, F g f r 1^{l o x / l o x} ; F g f r 3^{\text {null/null }} \mathrm{mu}$ tants (will be referred to as $F g f r 1^{-/-} ; F g f r 3^{-/-}$) at E11.5, there was a slightly increased percentage of TUNEL-labeled cells in the ventral medial area ( 0.8 vs $0.2 \%$ ) (Gutin et al., 2006). When we examined $\mathrm{Fgfr} 1^{-1-}$ and $\mathrm{Fgfr} 2^{-1-}$ mutants at E12.5, we observed a slight increase in TUNEL + cells in the mutants compared with controls, which was fairly widespread over the whole forebrain, including the dorsal regions (data not shown). Together, there was no evidence of massive cell death specifically in the ventral regions that could have ablated the majority of the OLP population, accounting for the dramatically reduced numbers of OLPs in the ventral forebrains of these mutants.

In the absence of evidence for either major alterations in OLP proliferation or regionally localized massive cell death in the ventral forebrain, we conclude that the dramatic decrease in the numbers of OLPs in the Fgfr1 ${ }^{-1-}$ or Fgfr $2^{-1-}$ mice is attributable to a decreased efficiency of their induction from the neuroepithelial cells of the forebrain. 
A
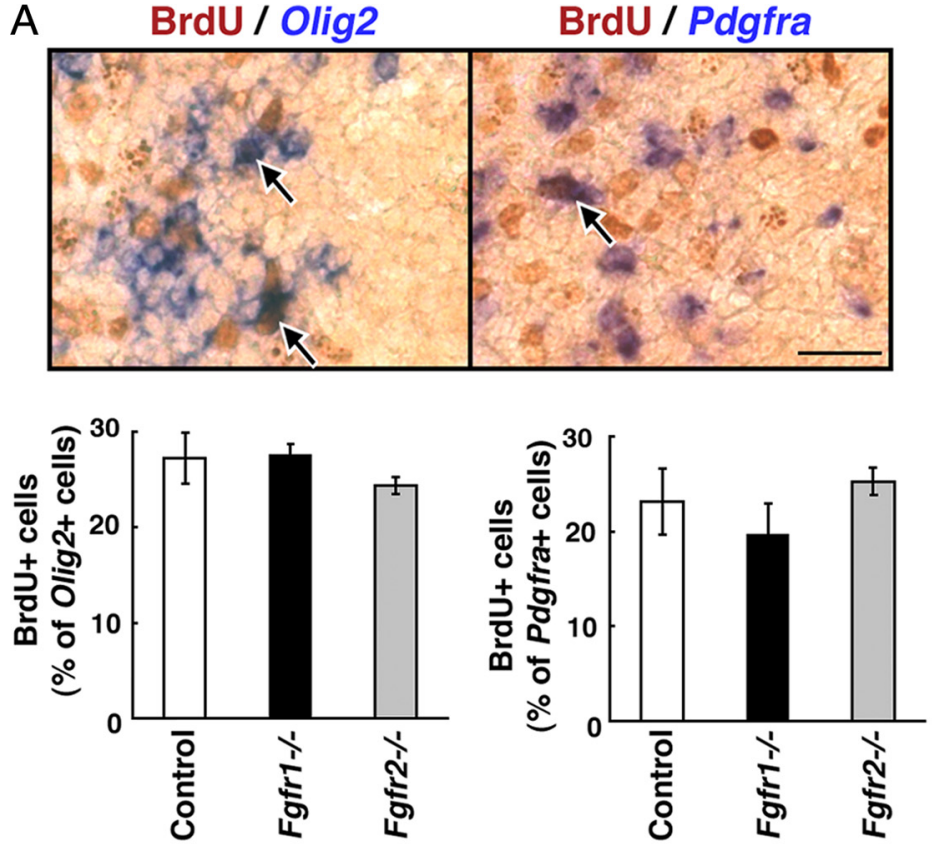

B
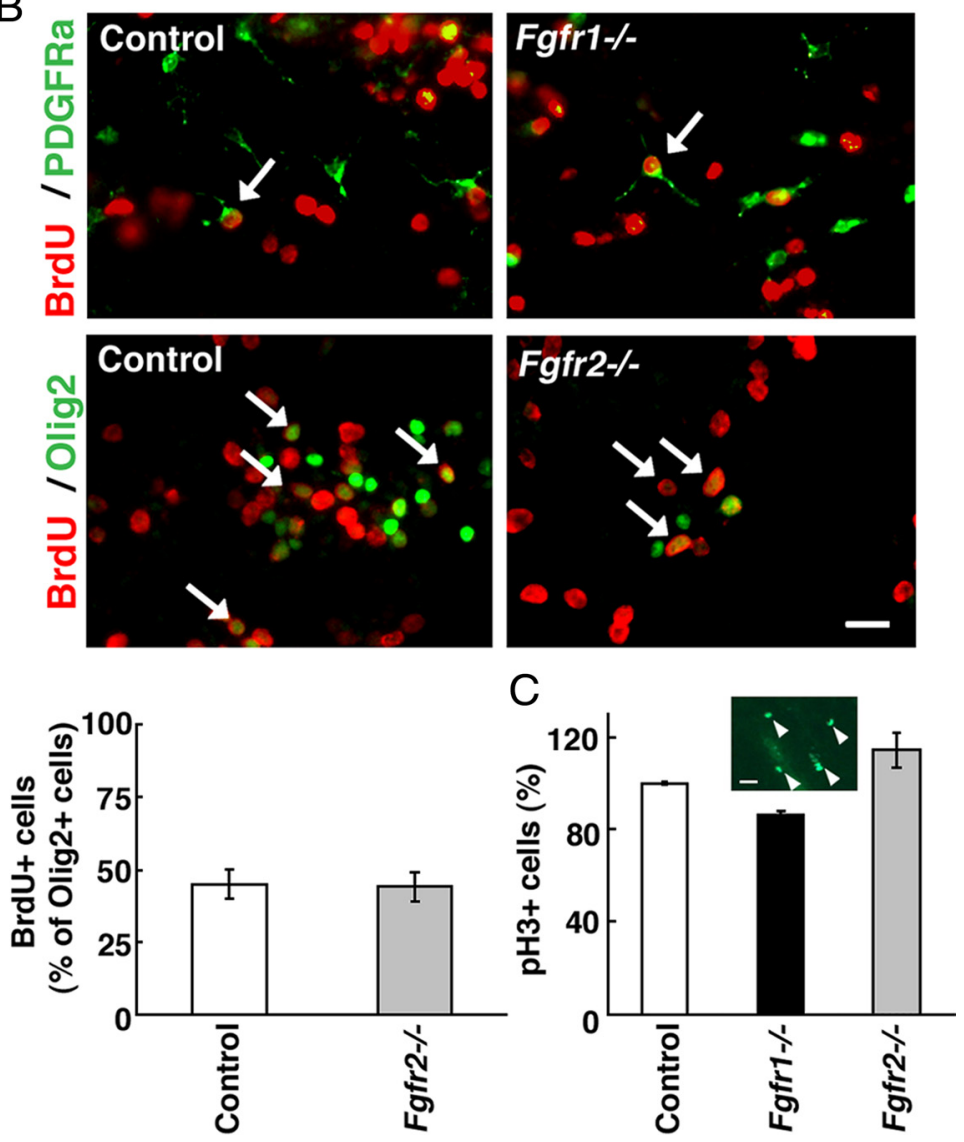

Figure 4. Loss of Fgfr1 or Fgfr2 does not affect proliferation of $0 \mathrm{~L}$ progenitors. $A$, Mothers were injected intraperitoneally with BrdU ( $100 \mathrm{mg} / \mathrm{kg}$ body weight $) 1 \mathrm{~h}$ before harvesting the embryos. To identify proliferating cells, coronal sections of E12.5 forebrain from Fgfr ${ }^{-1-}$ or Fgfr2 ${ }^{-1-}$ mutants and littermate control were double labeled by combining immunohistochemistry for BrdU (brown) and in situ hybridization for Olig2 or Pdgfra mRNA expression (purple). Total numbers of BrdU + cells double labeled for Pdgfra or Olig2 mRNA (arrows) were counted in the entire section as in Figure 1 and expressed as percentage of Olig2- or Pdgfrapositive cells. No significant differences were observed in the numbers of proliferating OLPs between controls and either of the mutants. Error bars represent SEM $(N=3-4)$. B, Dissociated cell cultures initiated from E12.5 forebrains of control, $F g f r 1^{-l-}$, or $\mathrm{Fgfr}^{-1-}$ embryos were treated with BrdU $(50 \mu \mathrm{m})$ for $3 \mathrm{~h}$ and cells were double immunolabeled with anti-BrdU and either anti-0lig2 (3 DIV) or anti-PDGFRa (6 DIV). No differences were observed in the numbers of 0lig2 + cells incorporating BrdU in control and $\mathrm{Fgfr}^{-1-}$ (quantified) or Fgfr $7^{-1-}$ mutant cultures. The arrows show examples of double-labeled cells. Error bar
Fgfr 1 and $F g f r 2$ gene dosages govern the extent of OL progenitor induction

Analysis of Fgfrl and Fgfr2 single mutants showed that loss of either Fgfrl or Fgfr2 was sufficient to attenuate the generation of the majority of OLPs from the ventral neuroepithelial precursors (Fig. 1). Nevertheless, a small population of OLPs appeared in these single mutants, suggesting that neither of the receptors could fully compensate for the other. To test this hypothesis, we examined mutants with deletion of different combinations of Fgfrl-3 genes. We also compared $F g f r 1^{-1-}$; Fgfr2 ${ }^{-1-}$ with $\mathrm{Fgfr}^{-1-} ; \mathrm{Fgfr} 3^{-1-}$ double mutants to determine whether deletion of any of the two receptors together would have the same effect on OLP generation. E12.5 forebrains were analyzed by in situ hybridization for the expression of $P d g f r a$ (Fig. 5A). Combined loss of both alleles of Fgfrl and Fgfr3 (Fgfr1 ${ }^{-/-} ; \mathrm{Fgfr} 3^{-/-}$) or one allele of $F g f r 1$ and both alleles of $F g f r 2$ $\left(F g f r 1^{+/-} ; F g f r 2^{-1-}\right)$ were not sufficient to cause a significant additional reduction of OLPs over single mutants of Fgfrl or Fgfr2. In contrast, elimination of Fgfr1 in combination with one or both alleles of Fgfr2 (Fgfr1 ${ }^{-1-} ; \mathrm{Fgfr} 2^{+/-}$or $\mathrm{Fgfr} 1^{-1-}$; $\left.F g f 2^{-1-}\right)$ led to a significant reduction or complete failure of OLP generation, respectively. It is important to note that in the $F g f r 1^{-I-} ; F g f 2^{-I-}$ double mutants, the telencephalon is dorsalized [evident by the absence of Olig2 expression in the ventral VZ (Fig. 5B) and other ventral markers (Gutin et al., 2006)], suggesting a loss of all the ventral precursor cells. Thus, it is likely that the complete absence of OLPs (and interneurons) (Gutin et al., 2006) in the double mutants $\left(F g f r 1^{-1-}\right.$; $\mathrm{Fgfr} 2^{-1-}$ ) could be secondary to a loss of all ventral precursor cells. However, the almost complete failure of OLP development in Fgfr1 ${ }^{-/-} ; \mathrm{Fgfr}^{+/-}$cannot be attributed to this fact, since ventral precursors were apparently present in these mutants, evident by normal Olig2 expression in the ventral VZ (Fig. 5B), and therefore normal dorsoventral patterning. It is

represents SEM for control $(N=3)$ and means of the difference for Fgfr $2^{-1-}(N=2)$. C, Coronal sections of E12.5 forebrain from control, $\mathrm{Fgfr}^{-1-}$, or $\mathrm{Fgfr} 2^{-1-}$ mice were immunostained with anti-pH3 (a marker for mitotic cells). Total numbers of pH3-positive scattered cells were counted in the entire section as for Figure 1 [representative area with $\mathrm{pH} 3+$ cells (arrowheads) is shown in inset], and the numbers were expressed as a percentage of the control. No differences in the numbers of $\mathrm{pH} 3+$ cells were observed between the control and mutants. Error bars represent mean of duplicates. Scale bars: $\boldsymbol{A}, 50 \mu \mathrm{m} ; \boldsymbol{B}, 20 \mu \mathrm{m} ; \boldsymbol{C}, 20 \mu \mathrm{m}$. 


\section{A Pdgfra}
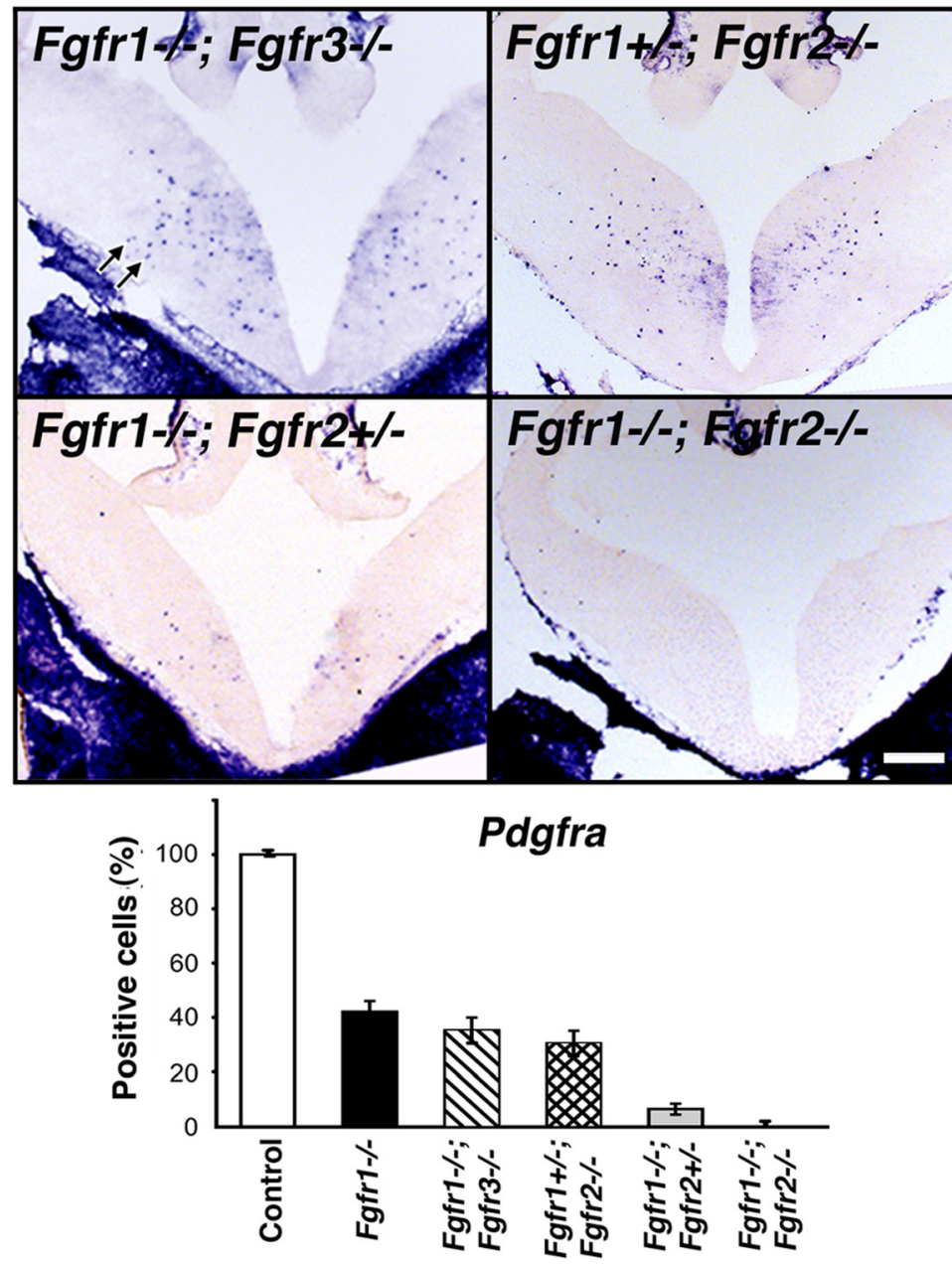

B

Olig2

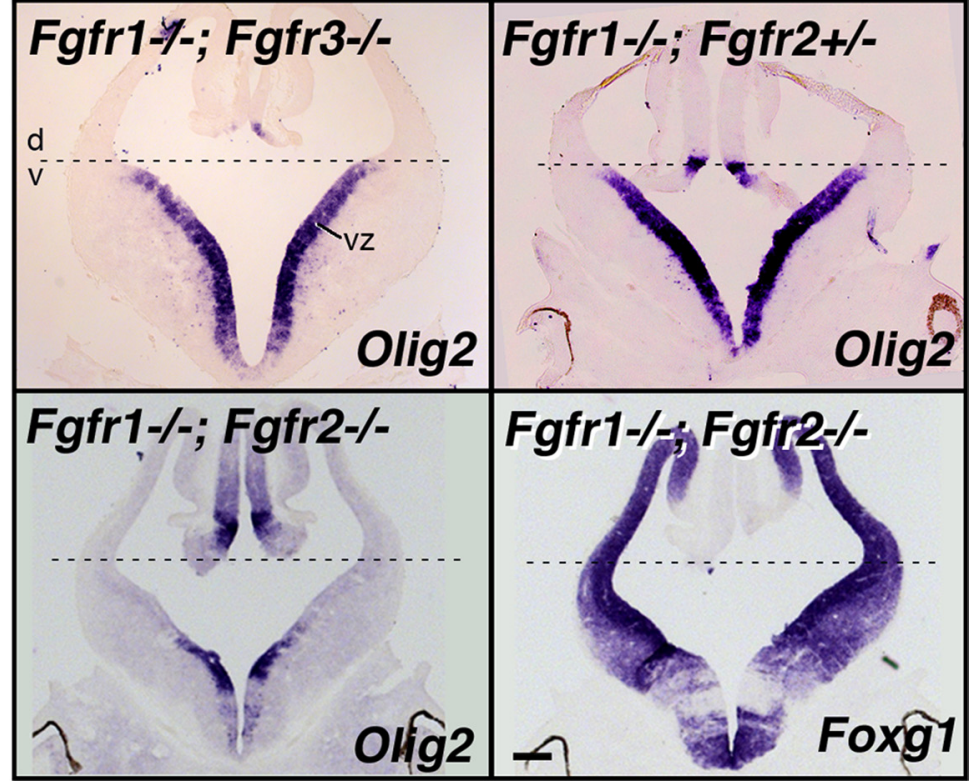

Figure 5. Fgfr 1 and Fgfr2 gene dosages govern the extent of $0 \mathrm{~L}$ progenitor induction. Coronal sections of E12.5 forebrain from control or mutants with different combinations of the three receptors deleted (Fgfr ${ }^{-1-} ; F g f r 3^{-1-}, F g f r 1^{+1-} ; F g f r 2^{-1-}$ $\mathrm{Fgfr}^{-1-} ; \mathrm{Fgfr}^{+1-}, \mathrm{Fgfr}^{-1-} ; \mathrm{Fgfr}^{-1-}$ ) were analyzed by in situ hybridization for the expression of Pdgfra (A), Olig2 and Foxg1 (B) mRNA. Three to four matched sections, each from three to four mice, were analyzed from each group. $\boldsymbol{A}$, Compared with also interesting to note that one allele of Fgfr2 was mostly sufficient for maintaining normal dorsoventral patterning (Fig. 5B).

We conclude that reducing the combined gene dosage of Fgfr 1 and Fgfr2 (but not Fgfr3) significantly influences the extent of OLP induction, with $F g f r 1$ playing a more dominant role than Fgfr2. These data emphasize the important difference between the three FGF receptors in influencing OLP generation in vivo.

Shh expression and signaling is unaffected in the ventral forebrains lacking individual or combined alleles of $F g f r 1$ and $F g f r 2$

Shh is a potent inducer of OLPs; therefore, it is plausible that the reduction of OLPs in the conditional Fgfr mutants could be indirect (i.e., loss of Fgfr signaling may downregulate Shh signaling, which in turn could adversely affect OLP generation). Previous studies addressed this question related to dorsoventral patterning in the Fgfr1 ${ }^{-1-} ; \mathrm{FgFr}^{-1-}$ double mutants at E10.5 and showed that Shh and its dependent gene Gli1 were unaffected in these mutants (Gutin et al., 2006). However, $\mathrm{Fgfr}^{-1-}$ and $\mathrm{Fgfr}^{-1-}$; Fgfr2 ${ }^{+/-}$mutants were not examined in this study. Given that, in the single $F g f 2^{-1-}$ mutant, unlike interneurons, OLP generation was significantly affected and that in the Fgfr1 ${ }^{-1-}$; $\mathrm{Fgfr}^{+1-}$ mutants it was virtually abolished (even when ventral precursors were present), it became essential to determine whether the expression and signaling potential of Shh in these mutants was compromised. We, therefore, examined these mutants for the first time and also extended previous studies and examined E12.5 embryos of single and double mutants of Fgfrl and Fgfr2 for the expression of Shh and its receptor Patched1, as a read-

the controls in mice lacking Fgfr 1 in combination with one or both alleles of Fgfr 2 , but not of Fgfr 3 , the numbers of $P d g f r a+$ OLPs (arrows) were dramatically reduced (Fgfr $1^{-1-}$; $\mathrm{Fgfr}^{+{ }^{+-}}$) or totally failed to develop $\left(\mathrm{Fgfr}^{-1-} ; \mathrm{Fgfr}^{-1-}\right)$. Error bars represent SEM $(N=3-4)$. B, Dorsal-ventral $(d, v)$ patterning, shown by the expression of Olig2 in the ventral VZ, remained intact in all mutants except in the $\mathrm{FgFr}^{-\mathrm{I}}$; Fgfr $2^{-1-}$ double mutant. Foxg1 and Olig2 expression patterns are shown in serial sections in these mutants to demonstrate the loss of Olig2 expression from the regions of the ventricular zone corresponding to regions of strong Foxg 1 expression (in which floxed Fgfr1 and Fgfr2 genes should be deleted by Foxg1-cre), but as expected, Olig2 remained in the regions mostly negative for Foxg1. Scale bars, $200 \mu \mathrm{m}$. Note the severe failure of Pdgfra + OLPs to develop in Fgfr ${ }^{-1-}$ Fgfr ${ }^{+/-}$mutants without disruption of $d$-v patterning. 
out gene of Shh signaling. Coronal sections from control and mutants taken from rostral (Fig. 6A) or caudal regions (Fig. 6B, C) of the forebrain were analyzed for Shh, Patched1, and Foxg1 mRNA expression by in situ hybridization of adjacent serial sections. Expression of Shh and Patched1 was not significantly altered in Foxg1+ region of the mutants in which floxed Fgfr genes should be deleted by Foxg1-cre (Foxg1 expression shown only for Fgfr $1^{-1-}$ and Fgfr1 ${ }^{-1-}$;Fgfr ${ }^{-1-}$ sections).

Thus, in the absence of a significant affect on Shh signaling in any of the mutants of Fgfr 1 and Fgfr2, we conclude that FGF receptor signaling acts either independently or downstream of Shh to control OLP generation.

Cooperation between sonic hedgehog and FGF receptor signaling is required for the generation of ventrally derived OL progenitor populations in vitro It has been shown that attenuation of Shh signaling in vivo and in cultures of embryonic forebrains results in a strong inhibition of OLP generation (Nery et al., 2001; Tekki-Kessaris et al., 2001; Fuccillo et al., 2004; Kessaris et al., 2004). In the present study, we showed that, like Shh, attenuation of Fgfr signaling in vivo also inhibits OLP generation not only in the double Fgfr1 ${ }^{-1-} ; F g f r 2^{-1-}$ mutants but also in the single Fgfr $1^{-1-}$ and Fgfr $2^{-1-}$ mutants (Figs. $1,5)$. To substantiate our in vivo loss-offunction genetic approach, we asked whether inhibition of OLP generation observed in vivo and in cultures of $F g f r 1^{-1-}$ or Fgfr $2^{-1-}$ mutants could be mimicked in cultures of normal forebrains grown in the presence of a specific chemical inhibitor of Fgfr signaling (PD173074). The specificity of this inhibitor for Fgfrs has been established previously where PD173074, at similar doses used in this experiment, specifically inhibited FGF-2-mediated but not PDGF-mediated mitogen-activated protein kinase (MAPK) activation and proliferation of isolated OLPs (Bansal et al., 2003b). Dissociated cell cultures derived from whole forebrains of wild-type E12.5 mice were cultured in defined media in the presence or absence of PD173074 (Fig. 7 A, B). OLP development

was analyzed by immunolabeling cells with specific markers of early and late OLPs (PDGFRa, O4). Hoechst staining of cell nuclei showed a similar distribution of total cells in cultures grown in the absence or presence of the inhibitor (Fig. 7A; supplemental Fig. 2, available at www.jneurosci.org as supplemental material). There was a dramatic reduction in the numbers of PDGFRa+ and O4+ OLPs that develop in these cultures in the presence of the Fgfr inhibitor. These data are consistent with our in vivo genetic loss-of-function results, but differ somewhat from a pre-

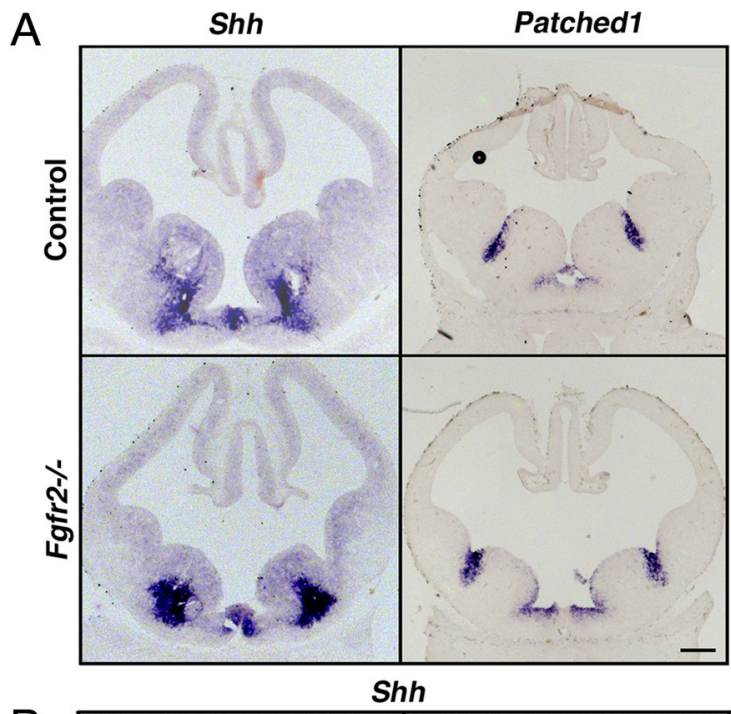

\section{Foxg1}

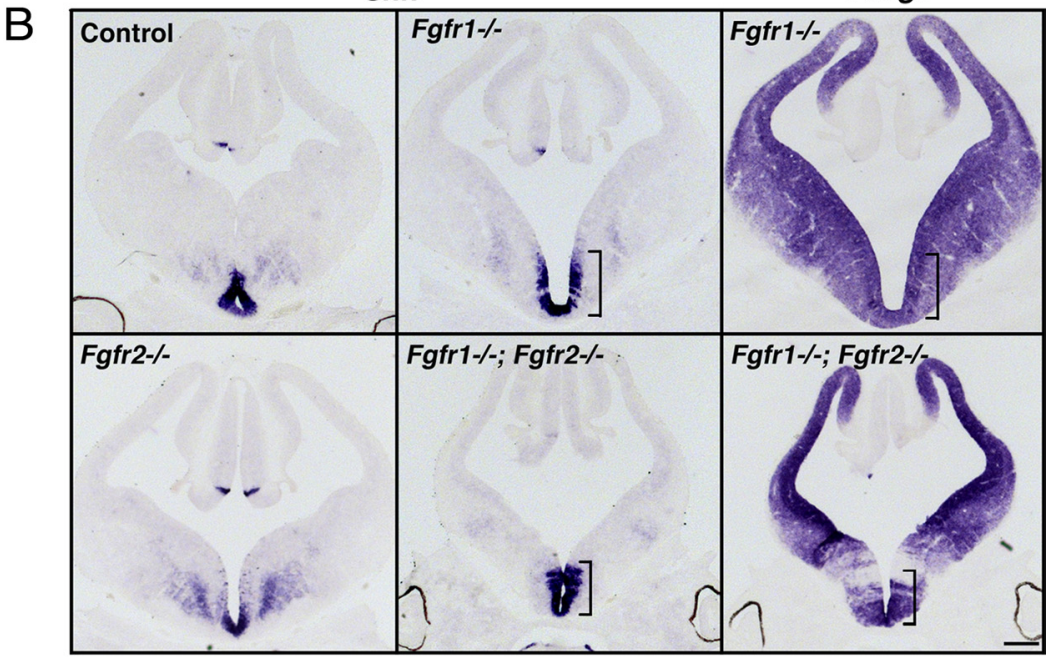

C

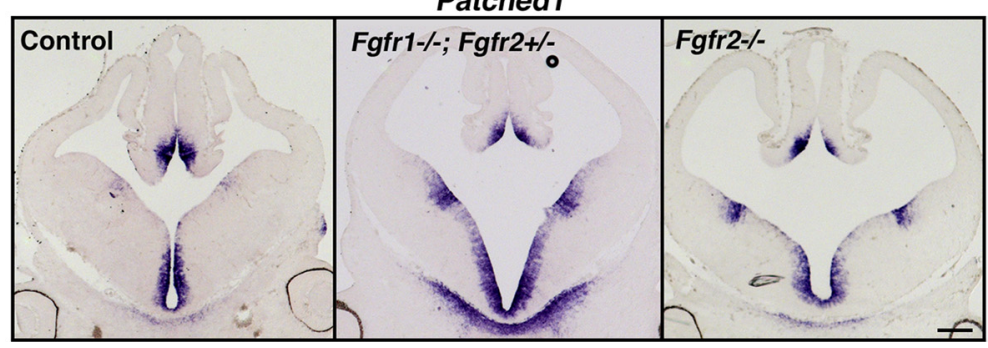

Figure 6. Shh and Patched1 expression is unaffected in the ventral forebrains lacking individual or both of Fgfr1 and Fgfr2. Coronal sections of E12.5 forebrain from single and double mutants of $F g f r 1$ and $F g f r 2$ and littermate controls taken from rostral $(A)$ or caudal $(\boldsymbol{B}, \boldsymbol{C})$ regions of the forebrains were analyzed by in situ hybridization for the expression of $S h h$ and its receptor Patched 1 (as a readout of Shh signaling). Expression of Shh and Patched 1 were not significantly affected in any of the mutants: Fgfr $2^{-/-}$ $(\boldsymbol{A}-\boldsymbol{C}), \mathrm{Fgfr}^{-1-}(\boldsymbol{B}), \mathrm{Fgfr}^{-1-} ; \mathrm{Fgfr}^{+/-}(\boldsymbol{C})$, or Fgfr $^{-1-} ; \mathrm{Fgfr}^{-/-}(\boldsymbol{B})$. In situ hybridization for Foxg 1 in adjacent sections of $\mathrm{Fgfr}^{-1-}$ or Fgfr ${ }^{-I-}$; Fgfr2 ${ }^{-I-}$ mutants show that Shh continues to be expressed in Foxg1 + region (brackets) in which floxed Fgfr $1 / 2$ genes should be deleted by Foxg1-cre. The same image of Foxg 1 was used in Figure 5B. Scale bar, $200 \mu \mathrm{m}$.

vious in vitro report that did not observe a decrease in the numbers of ventrally derived OLPs, defined by the expression of NG2, by PD173074 treatment (Kessaris et al., 2004). The difference could partly be attributable to the examination of a different OLP marker, NG2, that identifies a little different stage of OLP development than PDGFRa or O4. We were unable to duplicate these studies as in our cultures of embryonic forebrain; the NG2 antibody immunostained a much larger population of cells (many with a fibroblast-like morphology) than PDGFRa (data not 
A
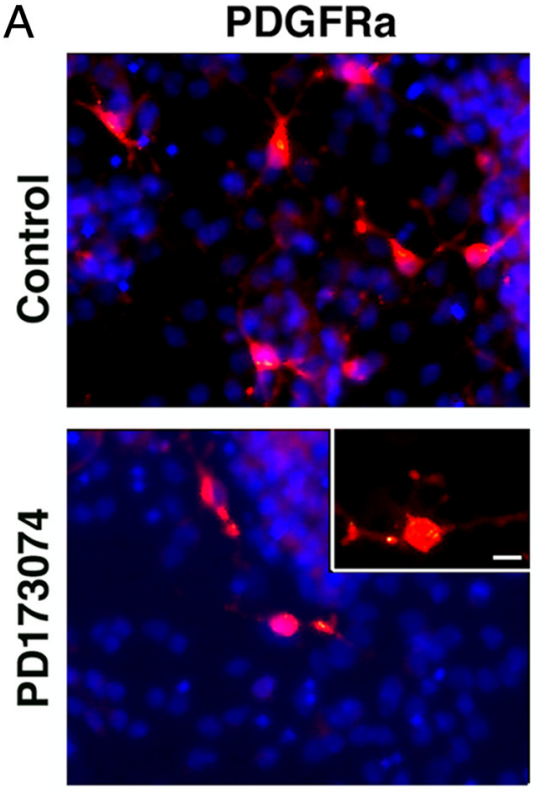

$\mathrm{B}$

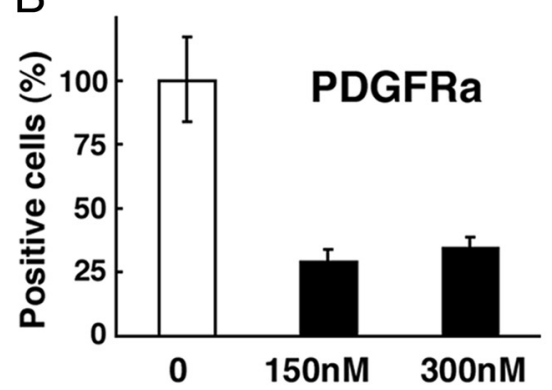

$\mathrm{C}$

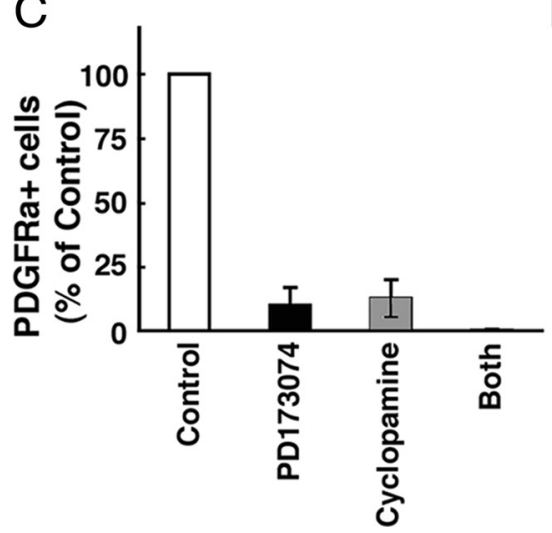

04
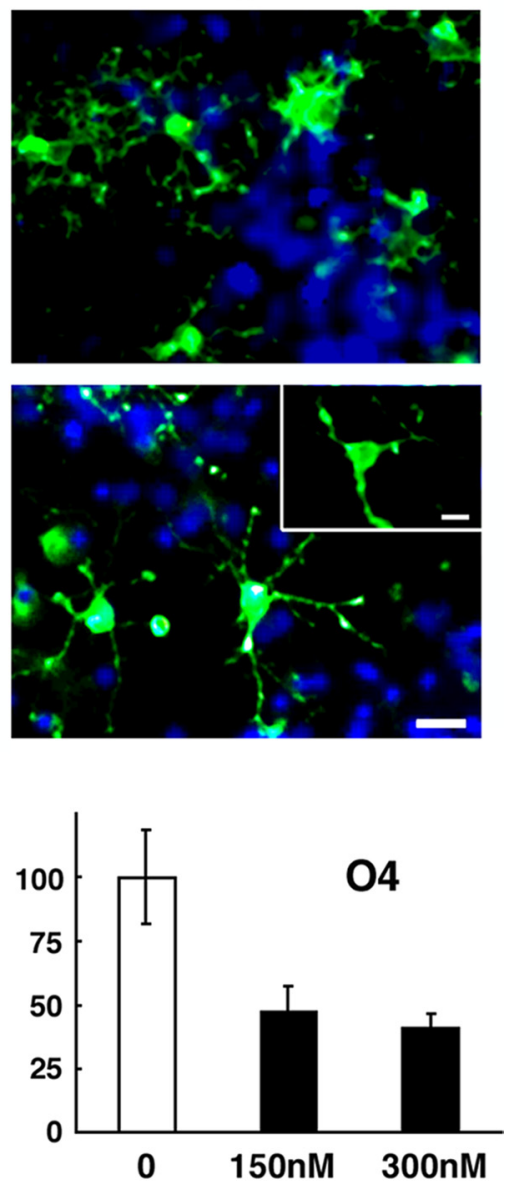

D

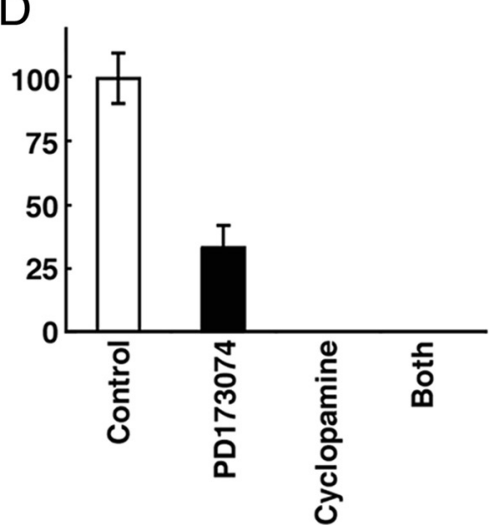

Figure 7. Cooperation between sonic hedgehog and FGF receptor signaling is required for the generation of ventrally derived $\mathrm{OL}$ progenitor population in vitro. Dissociated cell cultures initiated from whole forebrains of E12.5 wild-type mice $(\boldsymbol{A}-\boldsymbol{C})$ or from the ventral portion of the forebrain from E11.5 wild-type mice $(\boldsymbol{D})$ were grown in defined media in the presence or absence of a chemical inhibitor of Fgfrs [PD173074; $150 \mathrm{~nm}(\boldsymbol{A}-\boldsymbol{C}), 100 \mathrm{~nm}(\boldsymbol{D})$, or $300 \mathrm{~nm}(\boldsymbol{B})$ ], inhibitor of all hedgehogs (cyclopamine; $1 \mu \mathrm{M})$, or both. 0LP development was analyzed by immunolabeling with specific marker of early 0LPs (PDGFRa) at 6DIV (A-C) or 9DIV (D), late OLPs (04) at 9 DIV $(\boldsymbol{A}, \boldsymbol{B})$ double labeled with the nuclear marker Hoechst (blue). The total numbers of PDGFRa- or 04-positive cells were counted and expressed as a percentage of control. Error bars represent $S E M(N=3)$. Each experiment was performed at least two to three times. Scale bars, $50 \mu \mathrm{m}$. Note that OLP generation is strongly inhibited by either of the inhibitors.

shown). Given the current debate about the identity and fate of NG2 + cells (Zhu et al., 2008; Nishiyama et al., 2009; Trotter et al., 2010) and the difficulty we encountered in definitively identifying OLPs among the mixed population of cells immunostained by the NG2 antibody, we preferred to use PDGFRa and O4 to reliably mark OLPs in the cultures initiated from very early embryonic brains.
To investigate the relationship of FGF and Shh signaling in OLP generation, we next examined the effects of cyclopamine (hedgehog inhibitor) and PD173074, individually and in combination, in parallel dissociated cultures of not only whole E12.5 forebrains (Fig. $7 C$ ) but also of ventral E11.5 (Fig. 7D) and E10.5 (data not shown) forebrains for OLP generation. We found that the appearance of PDG$\mathrm{FRa}+$ OLPs in these cultures was strongly inhibited by either of the two inhibitors, individually or in combination, at each of the ages or regions examined.

From these data, we conclude that a cooperation between sonic hedgehog and FGF receptor signaling is required for the generation of the vast majority of ventrally derived OLPs, since loss of either one resulted in a severe attenuation of OLP induction. Importantly, these data also indicate that E12.5 forebrain cells, grown in defined media, must normally produce FGF (and Shh) endogenously at concentrations sufficient for the development of the vast majority of OLPs in these cultures.

Erk1/2 MAPKs are expressed in the ventral forebrain at the time of $O L$ progenitor generation and can be activated by FGF receptor stimulation Since the Ras/MAPK pathway is one of the major signaling pathways downstream of Fgfrs and, at least in the dorsal forebrain, has been implicated in the OLP-inducing activity of both Shh and FGF-2 (Kessaris et al., 2004), we next asked whether the ventral forebrain cells also expressed Erk1/2 MAPK, which could be activated by stimulating, and inhibited by attenuating Fgfr signaling. Immunolabeling of coronal sections of E12.5 forebrains with anti-pan-Erk $1 / 2$ showed a clear expression of Erk1/2 MAPK, both in the dorsal and ventral forebrain cells (Fig. 8A). The specificity of the Erk1/2 staining was confirmed by the absence of a positive signal in (1) non-neuronal tissue (Fig. $8 \mathrm{~A}$, asterisk), (2) in control serial section with no primary antibody (Fig. $8 B$ ), and (3) in brain sections from Erk1/2 knock-out mice (part of another study) (data not shown). In addition, immunoblotting of tissue from E12.5 ventral and dorsal forebrains, with anti-pan-Erk1/2, further demonstrated the presence of Erk1/2 in these regions (Fig. 8C).

To examine the effect of Fgfr stimulation on Erk1/2 MAPK activation, dorsal and ventral forebrain cells were freshly dissociated separately and incubated with FGF-2 or FGF-8. These FGFs are normally expressed in the embryonic forebrains and are considered physiological ligands for the three Fgfrs (Ford-Perriss et al., 2001). Immunoblot analysis of the cells showed that these 
FGFs dramatically increased Erk1/2 MAPK phosphorylation over basal levels both in the dorsal and ventral region cells (Fig. 8C). Inhibition of Fgfr signaling by PD173074 completely abolished not only the FGF-induced Erk1/2 MAPK phosphorylation but, importantly, the basal level as well. These data suggest that Fgfrs are clearly a major (if not the only) upstream regulator of Erk1/2 MAPK activity in the E12.5 forebrain.

We conclude that activation of the Erk1/2 MAPK pathway in the embryonic forebrain is very likely to play a primary role in the FGF-mediated induction of ventrally derived OLPs and perhaps of other lineages that emerge in a similar spatial and temporal manner.

\section{Discussion}

By conditionally deleting $F g f r 1-3$ in different combinations from the embryonic forebrain, we demonstrate that differential loss of Fgfr1 and Fgfr2 but not Fgfr3 genes results in a partial to complete failure of ventrally derived OLPs to develop, without a loss of Shh signaling, providing strong evidence for a direct role of Fgfr signaling in OLP generation. Furthermore, since OLP generation was strongly inhibited in vitro by attenuating either FGF or Shh signaling, we suggest that Fgfr cooperates with Shh to control OLP generation.

Dorsal forebrain and spinal cord neuroepithelial cells have the potential to generate OLPs under the influence of FGF-2 in vitro (Chandran et al., 2003; Gabay et al., 2003; Kessaris et al., 2004; Abematsu et al., 2006). However, the relevance of these studies in the context of the in vivo generation of OLPs has been questioned (Gabay et al., 2003). Furthermore, since the normal origin of the embryonically derived OLP population is the ventral and not the dorsal forebrain (Spassky et al., 1998; Nery et al., 2001; Tekki-Kessaris et al., 2001; Rowitch, 2004; Kessaris et al., 2008), these approaches, although informative about the potential of dorsal forebrain cells to generate OLPs, suffer from possible in vitro deregulatory effects and fail to directly address the role of FGF signaling in the normal generation of the embryonically derived OLP populations. Thus, the present study not only directly demonstrates the in vivo consequence of eliminating FGF signaling on OLP generation but also reveals the differential signaling potential of the three FGF receptors.

Exposure of isolated OLPs to FGF-2 in vitro leads to continuous proliferation, predicting a prominent role of FGF signaling in OLP proliferation (McKinnon et al., 1990; Bansal, 2002; Fortin et al., 2005). However, contrary to this notion, the present study shows that, in vivo, the loss of FGF signaling in Fgfr1 ${ }^{-1-}$ or Fgfr2 $2^{-1-}$ mutants does not affect OLP proliferation in the embryonic forebrain or in dissociated cultures derived from the embryonic mutant forebrains. Thus, the severe reduction of OLP population in the $F g f r 1^{-1-}$ and $F g f r 2^{-1-}$ mutants cannot be accounted for simply by inhibition of proliferation (or increased cell death) of specified cells. Furthermore, a potential inhibition of the migration of cells from the germinal zone is unlikely to account for the reduced numbers of scattered OLPs observed in the mutants, since similar reduction was observed in cultures of E12.5 mutant forebrains and of normal brains grown in the presence of a chemical inhibitor of FGF receptors. We, therefore, favor the hypothesis that, like Shh, FGF signaling generates ventral OLPs by directly promoting their specification. Consistent with the inductive role of FGF signaling in specifying ventral cells, FGF8-soaked beads ectopically induced ventral telencephalic cells (Kuschel et al., 2003); and FGF-2 infused into the ventricles induced OLPs in the neocortex and potentially in the ventral forebrain, judged by the increased numbers of OLPs in the cortical intermediate zone, the accepted migration route of ventrally derived OLPs (Naruse et al., 2006). Thus, although FGF signaling effects proliferation of OLPs in vitro, it is not essential for the proliferation of specified OLPs in vivo but is required for their induction from the neuroepithelial cells.

In addition to FGF, as shown here, it is well accepted that Shh induces the generation of OLPs from the ventral forebrain (Alberta et al., 2001; Nery et al., 2001; Spassky et al., 2001; TekkiKessaris et al., 2001; Fuccillo et al., 2004; Rowitch, 2004). This raises the question whether these molecules operate entirely independently or cooperatively, perhaps in a sequential manner. Our in vivo results, together with previous findings (Gutin et al., 2006), show that loss of Fgfr signaling in the mutant forebrains did not adversely affect Shh signaling, which suggests that atten- 
uated OLP generation in these mice is not simply attributable to downregulation of Shh signaling. To address this further, when we attenuated either Shh or Fgfr signaling in ventral forebrain cells by cyclopamine or PD173074, respectively, we found a strong inhibition of OLP induction by either of the inhibitors, suggesting that cooperation between FGF and Shh signaling must exist to generate the majority of ventrally derived embryonic populations of OLPs. Although the mechanism is currently unclear, given our present data and previous studies showing that several Fgf genes are downregulated in mice lacking Shh (Rash and Grove, 2007), and that Shh-induced OLP induction from the dorsal forebrain is blocked by attenuating FGF signaling in vitro (Kessaris et al., 2004), we favor the model that FGF functions downstream of Shh in the induction of ventrally derived OLPs. Our results from mouse forebrain analysis are consistent with the studies in zebrafish hindbrain, where loss of FGF receptor signaling resulted in the loss of OLP but not of Shh (Esain et al., 2010). The authors also suggest cooperation between FGF and Shh; specifically, Shh signaling establishes a progenitor domain that is competent to express Olig2, and Fgfr signaling permits or promotes Olig2 gene transcription (Esain et al., 2010). Another model proposed by Kessaris et al. (2004) for cooperative signaling between FGF and Shh, specifically for the dorsal forebrain cells, is that FGF receptor signaling maintains a basal level of MAPK phosphorylation, which is essential for Olig2 expression and the OLP-inducing activities of Shh. Together, it appears that Shh activity is not sufficient to generate OLPs and depends on FGF signaling for the generation of the vast majority of ventrally derived OLPs.

What are the mechanisms by which FGF receptor activation leads to OLP generation? Fgfrs are known to signal via two major phosphorylation cascades: the Ras/MAPK and the phosphatidylinositol 3-kinase/AKT pathway (Turner and Grose, 2010). In vitro evidence suggests that Erk1/2 MAPK pathway is a major contributor leading to the induction of OLPs, at least in the dorsal forebrain and spinal cord, since inhibition of Erk1/2 MAPK by a chemical inhibitor attenuated FGF-2-mediated induction of Olig2 cells in cultures of dorsal spinal cord or neocortex (Chandran et al., 2003; Kessaris et al., 2004). Our data show that the embryonic ventral forebrain cells also express Erk1/2 MAPK at the time of OLP generation, which is active at a basal level and can be further activated by stimulation of the Fgfrs by their physiological ligands, FGF-2 and FGF-8. Importantly, abolition of the basal level of active Erk1/2 by Fgfr-specific inhibitor suggests that Erk1/2 MAPK are exclusively controlled by Fgfr signaling in the E12.5 forebrain. Thus, it is plausible that activation of Erk1/2 MAPK downstream of Fgfrs plays a primary role in the FGF-mediated induction of OLPs from the embryonic ventral forebrain.

Previous studies showed that, in the Fgfr1 ${ }^{-I-}$; Fgfr ${ }^{-1-}$ double mutants, ventral precursor cells were lost and as a result interneurons failed to develop from the ventromedial telencephalon (Gutin et al., 2006), mimicking the phenotype of mice lacking Shh signaling (Ericson et al., 1995; Fuccillo et al., 2004; Xu et al., 2010). The present study shows that, in the double mutants, OLPs also failed to develop, as was shown for mice deficient in Shh signaling (Alberta et al., 2001; Nery et al., 2001; TekkiKessaris et al., 2001; Fuccillo et al., 2004; Rowitch, 2004), thereby providing strong genetic evidence that, like Shh, generation of both cell types is under the regulation of the same molecules. However, in the single Fgfr 1 and Fgfr2 mutants, where the ventral precursor cells are generated normally, some remarkable differences exist between interneuron and OLP generation. Specifically, in Fgfr1 single mutants, the generation of both interneurons
(Gutin et al., 2006) and OLPs (present study) was inhibited but to different extents; and in Fgfr 2 single mutants generation of OLPs was strongly inhibited but interneurons developed normally. This suggests that the nature of FGF signaling required for neuron or OLP generation from the neuroepithelial precursors may be somewhat different. The difference can be qualitative (i.e., Fgfr2 may activate certain pathways conducive for OLPs but not neurons). This connection of Fgfr2 with the OL lineage cells is also maintained in the adult brain, where Fgfr2 is localized primarily to OLs and myelin and not neurons (Miyake et al., 1996; Fortin et al., 2005). Another possible difference can be quantitative, where the generation of neurons and OLPs may depend on achieving different strengths of downstream signaling by the activated receptors. For example, it is possible that the strength or duration of Erk1/2 MAPK phosphorylation induced by Fgfr2 may be sufficient to promote OLP generation but not strong enough for interneuron generation, whereas the Fgfr1-induced phosphorylation of these molecules may be robust enough to acquire a critical signaling threshold needed for the generation of both cell types. This suggests differences in the signaling potential of individual Fgfrs. Consistent with this notion, the differential level of Erk1/2 MAPK phosphorylation was observed after the activation of distinct Fgfrs in the OL lineage cells (Fortin et al., 2005).

In summary, we provide novel evidence that $F g f r 1$ and $F g f r 2$, but not Fgfr3, have critical functions in the regulation of OLP generation from the embryonic mouse forebrain operating in cooperation with Shh.

\section{References}

Abematsu M, Kagawa T, Fukuda S, Inoue T, Takebayashi H, Komiya S, Taga T (2006) Basic fibroblast growth factor endows dorsal telencephalic neural progenitors with the ability to differentiate into oligodendrocytes but not gamma-aminobutyric acidergic neurons. J Neurosci Res 83:731-743

Aboitiz F, Montiel J (2007) Co-option of signaling mechanisms from neural induction to telencephalic patterning. Rev Neurosci 18:311-342.

Alberta JA, Park SK, Mora J, Yuk D, Pawlitzky I, Iannarelli P, Vartanian T, Stiles CD, Rowitch DH (2001) Sonic hedgehog is required during an early phase of oligodendrocyte development in mammalian brain. Mol Cell Neurosci 18:434-441.

Baas D, Barnstable CJ (1998) HPC-7: a novel oligodendrocyte lineage protein, which appears prior to galactocerebroside. Glia 23:169-179.

Bansal R (2002) Fibroblast growth factors and their receptors in oligodendrocyte development: implications for demyelination and remyelination. Dev Neurosci 46:24-35.

Bansal R, Kumar M, Murray K, Morrison RS, Pfeiffer SE (1996) Regulation of FGF receptors in the oligodendrocyte lineage. Mol Cell Neurosci 7:263-275.

Bansal R, Lakhina V, Remedios R, Tole S (2003a) Expression of FGF receptors 1, 2, 3 in the embryonic and postnatal mouse brain compared with Pdgfr alpha, Olig2 and Plp/dm20: implications for oligodendrocyte development. Dev Neurosci 25:83-95.

Bansal R, Magge S, Winkler S (2003b) Specific inhibitor of FGF receptor signaling: FGF-2-mediated effects on proliferation, differentiation and MAPK activation are inhibited by PD173074 in oligodendrocyte-lineage cells. J Neurosci Res 74:486-493.

Cai J, Qi Y, Hu X, Tan M, Liu Z, Zhang J, Li Q, Sander M, Qiu M (2005) Generation of oligodendrocyte precursor cells from mouse dorsal spinal cord independent of Nkx6 regulation and Shh signaling. Neuron 45:41-53.

Chandran S, Kato H, Gerreli D, Compston A, Svendsen CN, Allen ND (2003) FGF-dependent generation of oligodendrocytes by a hedgehogindependent pathway. Development 130:6599-6609.

Deng C, Wynshaw-Boris A, Zhou F, Kuo A, Leder P (1996) Fibroblast growth factor receptor 3 is a negative regulator of bone growth. Cell 84: 911-921.

Ericson J, Muhr J, Placzek M, Lints T, Jessell TM, Edlund T (1995) Sonic 
hedgehog induces the differentiation of ventral forebrain neurons: a common signal for ventral patterning within the neural tube. Cell 81:747-756.

Esain V, Postlethwait JH, Charnay P, Ghislain J (2010) FGF-receptor signalling controls neural cell diversity in the zebrafish hindbrain by regulating Olig2 and sox9. Development 137:33-42.

Espinosa-Jeffrey A, Wakeman DR, Kim SU, Snyder EY, de Vellis J (2009) Culture system for rodent and human oligodendrocyte specification, lineage progression, and maturation. Curr Protoc Stem Cell Biol 2:2D.4.

Ford-Perriss M, Abud H, Murphy M (2001) Fibroblast growth factors in the developing central nervous system. Clin Exp Pharmacol Physiol 28: 493-503.

Fortin D, Rom E, Sun H, Yayon A, Bansal R (2005) Distinct fibroblast growth factor (FGF)/FGF receptor signaling pairs initiate diverse cellular responses in the oligodendrocyte lineage. J Neurosci 25:7470-7479.

Fuccillo M, Rallu M, McMahon AP, Fishell G (2004) Temporal requirement for hedgehog signaling in ventral telencephalic patterning. Development 131:5031-5040.

Gabay L, Lowell S, Rubin LL, Anderson DJ (2003) Deregulation of dorsoventral patterning by FGF confers trilineage differentiation capacity on CNS stem cells in vitro. Neuron 40:485-499.

Gutin G, Fernandes M, Palazzolo L, Paek H, Yu K, Ornitz DM, McConnell SK, Hébert JM (2006) FGF signalling generates ventral telencephalic cells independently of $S H H$. Development 133:2937-2946.

Hébert JM (2005) Unraveling the molecular pathways that regulate early telencephalon development. Curr Top Dev Biol 69:17-37.

Hébert JM, McConnell SK (2000) Targeting of cre to the Foxg1 (BF-1) locus mediates loxP recombination in the telencephalon and other developing head structures. Dev Biol 222:296-306.

Hébert JM, Lin M, Partanen J, Rossant J, McConnell SK (2003) FGF signaling through FGFR1 is required for olfactory bulb morphogenesis. Development 130:1101-1111.

Kaga Y, Shoemaker WJ, Furusho M, Bryant M, Rosenbluth J, Pfeiffer SE, Oh L, Rasband M, Lappe-Siefke C, Yu K, Ornitz DM, Nave KA, Bansal R (2006) Mice with conditional inactivation of FGF receptor-2 signaling in oligodendrocytes have normal myelin but display dramatic hyperactivity when combined with Cnp1 inactivation. J Neurosci 26:12339-12350.

Kessaris N, Jamen F, Rubin LL, Richardson WD (2004) Cooperation between sonic hedgehog and fibroblast growth factor/MAPK signalling pathways in neocortical precursors. Development 131:1289-1298.

Kessaris N, Pringle N, Richardson WD (2008) Specification of CNS glia from neural stem cells in the embryonic neuroepithelium. Philos Trans R Soc Lond B Biol Sci 363:71-85.

Kuschel S, Rüther U, Theil T (2003) A disrupted balance between Bmp/Wnt and Fgf signaling underlies the ventralization of the Gli3 mutant telencephalon. Dev Biol 260:484-495.

Mason I (2007) Initiation to endpoint: the multiple roles of fibroblast growth factors in neural development. Nat Rev Neurosci 8:583-596.

McKinnon RD, Matsui T, Dubois-Dalcq M, Aaronson SA (1990) FGF modulates the PDGF-driven pathway of oligodendrocyte development. Neuron 5:603-614.
Miller RH (2002) Regulation of oligodendrocyte development in the vertebrate CNS. Prog Neurobiol 67:451-467.

Miyake A, Hattori Y, Ohta M, Itoh N (1996) Rat oligodendrocytes and astrocytes preferentially express fibroblast growth factor receptor-2 and -3 mRNAs. J Neurosci Res 45:534-541.

Naruse M, Nakahira E, Miyata T, Hitoshi S, Ikenaka K, Bansal R (2006) Induction of oligodendrocyte progenitors in dorsal forebrain by intraventricular microinjection of FGF-2. Dev Biol 297:262-273.

Nery S, Wichterle H, Fishell G (2001) Sonic hedgehog contributes to oligodendrocyte specification in the mammalian forebrain. Development 128:527-540

Nishiyama A, Komitova M, Suzuki R, Zhu X (2009) Polydendrocytes (NG2 cells): multifunctional cells with lineage plasticity. Nat Rev Neurosci 10:9-22.

Pfeiffer SE, Warrington AE, Bansal R (1993) The oligodendrocyte and its many cellular processes. Trends Cell Biol 3:191-197.

Qian X, Davis AA, Goderie SK, Temple S (1997) FGF2 concentration regulates the generation of neurons and glia from multipotent cortical stem cells. Neuron 18:81-93.

Rash BG, Grove EA (2007) Patterning the dorsal telencephalon: a role for sonic hedgehog? J Neurosci 27:11595-11603.

Rowitch DH (2004) Glial specification in the vertebrate neural tube. Nat Rev Neurosci 5:409-419.

Skaper SD, Kee WJ, Facci L, Macdonald G, Doherty P, Walsh FS (2000) The FGFR1 inhibitor PD 173074 selectively and potently antagonizes FGF-2 neurotrophic and neurotropic effects. J Neurochem 75:1520-1527.

Spassky N, Goujet-Zalc C, Parmantier E, Olivier C, Martinez S, Ivanova A, Ikenaka K, Macklin W, Cerruti I, Zalc B, Thomas JL (1998) Multiple restricted origin of oligodendrocytes. J Neurosci 18:8331-8343.

Spassky N, Heydon K, Mangatal A, Jankovski A, Olivier C, Queraud-Lesaux F, Goujet-Zalc C, Thomas JL, Zalc B (2001) Sonic hedgehog-dependent emergence of oligodendrocytes in the telencephalon: evidence for a source of oligodendrocytes in the olfactory bulb that is independent of PDGFRalpha signaling. Development 128:4993-5004.

Tekki-Kessaris N, Woodruff R, Hall AC, Gaffield W, Kimura S, Stiles CD, Rowitch DH, Richardson WD (2001) Hedgehog-dependent oligodendrocyte lineage specification in the telencephalon. Development 128:2545-2554.

Trotter J, Karram K, Nishiyama A (2010) NG2 cells: properties, progeny and origin. Brain Res Rev 63:72-82.

Turner N, Grose R (2010) Fibroblast growth factor signalling: from development to cancer. Nat Rev Cancer 10:116-129.

Xu Q, Guo L, Moore H, Waclaw RR, Campbell K, Anderson SA (2010) Sonic hedgehog signaling confers ventral telencephalic progenitors with distinct cortical interneuron fates. Neuron 65:328-340.

Yu K, Xu J, Liu Z, Sosic D, Shao J, Olson EN, Towler DA, Ornitz DM (2003) Conditional inactivation of FGF receptor 2 reveals an essential role for FGF signaling in the regulation of osteoblast function and bone growth. Development 130:3063-3074.

Zhu X, Bergles DE, Nishiyama A (2008) NG2 cells generate both oligodendrocytes and gray matter astrocytes. Development 135:145-157. 